\title{
The Complex Management of Atrial Fibrillation and Cancer in the COVID-19 Era: Drug Interactions, Thromboembolic Risk, and Proarrhythmia
}

\author{
Milo Gatti ${ }^{1}$ - Emanuel Raschi ${ }^{1}$ - Elisabetta Poluzzi ${ }^{1} \cdot$ Cristian Martignani $^{2} \cdot$ Stefania Salvagni $^{3} \cdot$ Andrea Ardizzoni $^{4}$. \\ Igor Diemberger ${ }^{2}$
}

Published online: 6 October 2020

(C) The Author(s) 2020

\begin{abstract}
Purpose of Review Cardiotoxicity by anticancer agents has emerged as a multifaceted issue and is expected to affect both mortality and morbidity. This review summarizes clinical challenges in the management of oncological patients requiring anticoagulants for atrial fibrillation (AF) also considering the current outbreak of the COVID-19 (coronavirus disease 2019) pandemic, since this infection can add challenges to the management of both conditions. Specifically, the aims are manyfold: (1) describe the evolving use of direct oral anticoagulants (DOACs) in AF patients with cancer; (2) critically appraise the risk of clinically important drug-drug interactions (DDIs) between DOACs and oral targeted anticancer agents; (3) address expected DDIs between DOACs and candidate anti-COVID drugs, with implications on management of the underlying thrombotic risk; and (4) characterize the proarrhythmic liability in cardio-oncology in the setting of COVID-19, focusing on QT prolongation. Recent Findings AF in cardio-oncology poses diagnostic and management challenges, also due to the number of anticancer drugs recently associated with AF onset/worsening. Oral targeted drugs can potentially interact with DOACs, with increased bleeding risk mainly due to pharmacokinetic DDIs. Moreover, the vast majority of oral anticancer agents cause QT prolongation with direct and indirect mechanisms, potentially resulting in the occurrence of torsade de pointes, especially in susceptible patients with COVID-19 receiving additional drugs with QT liability.

Summary Oncologists and cardiologists must be aware of the increased bleeding risk and arrhythmic susceptibility of patients with AF and cancer due to DDIs. High-risk individuals with COVID-19 should be prioritized to target preventive strategies, including optimal antithrombotic management, medication review, and stringent monitoring.
\end{abstract}

Keywords Anticancer agents · Direct oral anticoagulants · Atrial fibrillation · QT prolongation $\cdot$ COVID-19 $\cdot$ Drug-drug interactions

\section{Background}

In parallel with the advancements of chemotherapy, targeted therapy, immunotherapy, and radiotherapy, cardio-oncology

Milo Gatti and Emanuel Raschi contributed equally to this work.

This article is part of the Topical Collection on Cardio-Oncology

Igor Diemberger

igor.diemberger@unibo.it

1 Department of Medical and Surgical Sciences, Alma Mater Studiorum - University of Bologna, Bologna, Italy

2 Cardiology Unit, Department of Experimental, Diagnostic and Specialty Medicine, Alma Mater Studiorum - University of Bologna, Bologna, Italy has become a recognized medical specialty and clinicians are increasingly facing the multifaceted spectrum of cardiovascular toxicities by anticancer agents, with risk stratification, prevention, and early recognition being major emerging challenges $[1 \bullet \cdot, 2]$.

3 Division of Oncology, S. Orsola-Malpighi Hospital, Bologna, Italy

4 Medical Oncology Unit, Department of Experimental, Diagnostic and Specialty Medicine, Policlinico S. Orsola-Malpighi, Alma Mater Studiorum - University of Bologna, Bologna, Italy 
Cardiovascular toxicity with anticancer drugs is a rapidly evolving topic since it appears that no anticancer drug is fully devoid of cardiovascular liability. Historically, the original focus of cardio-oncology was on cardiotoxicity of oldfashioned chemotherapeutics, namely, delayed irreversible left ventricular ejection fraction impairment by anthracyclines, more recently shifting to targeted therapy, including reversible myocardial dysfunction by trastuzumab $[3,4]$. With the advent of third-generation targeted therapy, including immunotherapy, venous thromboembolism, arterial toxic effects, myocarditis with immune checkpoint inhibitors, and cardiac dysfunction in the setting of cytokine release syndrome with chimeric antigen receptor $\mathrm{T}$ cell therapy have gained greater recognition and are receiving attention due to severity and high fatality rates. This is particularly relevant in view of the improved survival gained by oncologic patients after the introduction of these agents $[5,6]$.

In the oncological setting, the use of antithrombotic drugs, especially direct oral anticoagulants (DOACs), is expected to substantially increase in the near future for different reasons, namely, improved patient survival; the high prevalence of drug- and cancer-associated thrombosis; the intertwined relationship between cancer and atrial fibrillation (AF), including the emerging case of drug-induced AF by anticancer drugs; and the ongoing coronavirus disease 2019 (COVID-19) pandemic that poses further challenges in this intricate scenario, including proarrhythmia due to multiple QT-prolonging mechanisms. Clinicians should balance the therapeutic benefit versus the theoretical risk of drug-drug interactions (DDIs) to achieve the optimal safe prescribing.

Therefore, this review is aimed at (1) summarizing the evolving use of DOACs in AF patients with cancer; (2) critically appraising the risk of clinically important DDIs between DOACs and oral targeted anticancer agents; (3) addressing expected DDIs between DOACs and candidate anti-COVID drugs, with implications on management of the underlying thrombotic risk; and (4) characterizing the proarrhythmic liability in cardio-oncology in the setting of COVID-19, focusing on QT prolongation.

\section{Evolving Use of DOACs in AF Patients With Cancer: an Update}

There is a close relationship between cancer and AF. In the ORBIT-AF registry, history of cancer was present in about a quarter of the 9749 patients analyzed. In particular, in 57\%, it was a solid cancer, while in $1.3 \%$, it was leukemia and in $3.3 \%$ a lymphoma. Notably, these patients presented a higher mortality coupled with increased risk of major bleedings [7]. Several studies confirmed the association between AF and cancer. In particular, the onset of AF was associated with a 2.5-fold increased absolute risk of a new diagnosis of cancer within the following 3 months (over 5 times greater than nonAF patients) [8], while in patients with a new diagnosis of cancer, there was a concomitant new diagnosis of $\mathrm{AF}$ in $2.4 \%$, with doubled thromboembolic risk and a 6 times greater risk of heart failure [9]. Interestingly, this reciprocal interference was confirmed by a specific subanalysis of the Women's Health Study [10]. Focusing on clinical outcomes, the ORBIT-AF registry and the ARISTOTLE trial did not highlight a different thromboembolic risk in patients with cancer with respect to the others; however, the number of incident active cancers was low, while in many patients, there was a history of cancer $[11,12]$. Interestingly, focusing into de novo diagnosis of cancer or relapses in the ENGAGE AF-TIMI 48 study, Fanola et al. [13] confirmed overall a similar thromboembolic risk with respect to the remaining population but with an excess of events in patients with solid cancer vs. hematologic/dermatologic neoplasia (HR, 3.92; 95\% CI, 121-127). Noteworthily, in all these studies, enrolled patients were candidates to DOACs in view of a CHADSVASC $\geq 2$. However, looking at low-grade CHADSVASC scores (i.e., 0 $[1 \bullet \cdot])$, patients with cancer had an increased risk of both thromboembolic and bleeding events, according to the Danish registry [14]. As such, it remains unclear which scoring system (CHA2DS2-VASc or CHADS2) is preferable in the cancer population [15].

The introduction of DOACs for thromboembolic prophylaxis in AF patients with active cancer was hampered by the known thrombophilic/coagulopathic state of active malignancy and exclusion of known cancer patients from DOAC pivotal trials. Available evidence is in favor of DOACs also in this setting, but it derives from subanalysis and observational studies. In the ARISTOTLE trial, apixaban offered greater protection than warfarin in the primary endpoint among 1236 patients with a history of active/ prior cancer [11]. In the ENGAGE AF-TIMI 48 trial, edoxaban showed significant improvement in the composite efficacy endpoint versus warfarin among 1153 patients with newly diagnosed cancer or disease recurrence [13]. Beyond these analyses, there are several observational studies confirming superiority vs. warfarin, but a proper trial is still lacking. It is also important to acknowledge that while low-molecular weight heparin (LMWH) is often a preferred anticoagulant to treat deep vein thrombosis/pulmonary embolism (DVT/PE) in cancer patients, there are no trials assessing the long-term efficacy and safety of LMWH in patients with $\mathrm{AF}$ to prevent thromboembolism [16]. In this regard, it is interesting to mention the ongoing Edoxaban for the Treatment of Coagulopathy in Patients With Active Cancer and Acute Ischemic Stroke (ENCHASE) study (Clinicaltrials.gov number: NCT03570281), which will compare edoxaban with LMWH for secondary prophylaxis in cancer-related stroke patients. This is relevant since despite the common use of LMWH in these 
patients, it has to be remembered that their use in acute stroke should be avoided $[17 \bullet \bullet]$.

Thrombocytopenia and renal failure are comorbidities commonly found in cancer patients, which decrease the safety margin of DOACs and in general for anticoagulation. Similar to the assessment of thromboembolic risk, there is no score for estimating bleeding risk in cancer patients, and the widely adopted (despite the recognized limitations) HAS-BLED score does not incorporate thrombocytopenia. Moreover, pre-approved DOAC trials excluded patients with platelet values $<90,000-100,000$. Regarding renal failure, it is known that its prevalence is frequent among patients with active cancer (e.g., in general, a GFR $<60 \mathrm{ml} / \mathrm{min}$ is present in $>15 \%$ of these subjects) and up to $80 \%$ of these patients are treated with nephrotoxic drugs [18]. Notably, acute kidney injury is recognized as a major complication of several chemotherapy treatments (affecting overall mortality), but suboptimal dose tailoring is frequent also in view of the limitations of the formulas to estimate renal function in these particular settings [19, 20]. For all these reasons, use of DOACs in cancer patients has to be considered also for thromboembolic prophylaxis in case of AF but this treatment should entail more frequent check for platelet counts, hemoglobin, and renal function than in standard AF population.

\section{Drug-Drug Interactions Between Targeted Anticancer Agents and Direct Oral Anticoagulants: a Bidirectional Concern?}

As anticipated, the close relationship between cancer and preexisting or new-onset AF [21] likely results in concomitant use of anticancer agents and DOACs, thus posing different concerns regarding occurrence of clinically relevant DDIs.

Although DOACs have minimal effects on the expression or activity of transporters or key CYP450 enzymes, actual impact on pharmacokinetic (PK) of anticancer agents is not expected; they are substrates for P-glycoprotein (P-gp) and therefore are all susceptible to agents modulating P-gp. Furthermore, all DOACs undergo liver metabolism, although CYP-dependent pathways are involved only for rivaroxaban and apixaban [22]. Consequently, the theoretical risk of interactions (mainly metabolic) appears to differ among DOACs as follows: rivaroxaban $>$ apixaban $>$ dabigatran $\approx$ edoxaban [23]. A summary of potential DDIs between DOACs and anticancer agents is shown in Table 1, where only oral targeted drugs are presented considering the role of the aforementioned metabolic liability as the main PK mechanism of interaction.

Among several potential DDIs occurring between DOACs and oral anticancer agents, only the concomitant administration of apixaban and idelalisib should be avoided, according to the specific online tool (https://www.cancer-druginteractions. org/), due to the strong inhibitory effect of idelalisib on CYP3A4 activity [24], although no real-world data exist. Furthermore, different anticancer agents show moderate/ strong inhibition (namely, erlotinib, gefitinib, lapatinib, imatinib, nilotinib, ceritinib, ribociclib, ibrutinib, ruxolitinib, venetoclax, olaparib, capmatinib, entrectinib, and letrozole) or induction (namely, brigatinib, lorlatinib, dabrafenib, vemurafenib, and enzalutamide) activity on CYP3A4 or P$\mathrm{gp}$, potentially leading to anticoagulant over- or undertreatment (Table 1). Particularly, ribociclib exhibits strong inhibitory effect on CYP3A4 when used at high dose $(600 \mathrm{mg} /$ day); thus, concomitant use of apixaban or rivaroxaban should be avoided due to potential risk of severe anticoagulant overexposure [25]. Conversely, concomitant use of apixaban or rivaroxaban and enzalutamide (strong CYP3A4 inducer) should be avoided, considering the expected associated risk of anticoagulant underexposure [26]. Although PK/PD monitoring is not required for DOACs in clinical practice, and no trials support this approach, the aforementioned selected scenarios might be considered to assess the actual need for therapeutic drug monitoring. Clinicians should be reminded on the importance of critically reading the summary of product characteristics (SPCs) and publicly available online tools on the risk of DDIs (https://www. cancer-druginteractions.org/).

To the best of our knowledge, PK studies or case reports exploring clinical relevance of these DDIs between DOACs and anticancer agents are available only for dabigatran with erlotinib [27], bosutinib [28], ibrutinib [29-31], and crizotinib [32] and for apixaban with ibrutinib [33, 34], cobimetinib [35], and cabozantinib [36]. To address the discrepancy between theoretical pharmacological basis and actual clinical impact, there is urgent need to exploit big data such as pharmacovigilance and healthcare databases in identifying and prioritizing relevant DDIs. Moreover, preclinical studies present the limitation to investigate the interaction between single agents while it is common practice to have multiple drug schemes, including potential concomitant administration of multiple chemotherapies, antibiotics, antiarrhythmics, and even antiplatelet agents. These combinations create a specific milieu which is hard to face in view of the multiple cross-reactions as pointed out in simpler settings by the European Society of Cardiology consensus document on DOAC use [17••]. The concept rising from these considerations is the presence of a "coagulation reserve," namely, an individual equilibrium between thrombotic and antithrombotic determinants at a certain time, affected by several concomitant factors (i.e., age, polypharmacy, underlying diseases, and organ failure), similar to the "repolarization reserve" present for the risk of development of torsade de pointes (TdP) [37], making clinically relevant a DDI also in cases where a relevant interaction is not expected according to pharmacological prediction. 
Table 1 Predicted pharmacokinetic drug interactions between main oral anticancer agents and direct oral anticoagulants

\begin{tabular}{|c|c|c|c|c|c|c|}
\hline & & \multicolumn{4}{|c|}{$\begin{array}{l}\text { DDIs with DOACs } \\
\text { (PK or PD prediction) }\end{array}$} & \\
\hline & & Dabigatran & Rivaroxaban & Apixaban & Edoxaban & \\
\hline \multicolumn{2}{|l|}{ P-gp substrate } & Yes & Yes & No (minimal) & Yes & \\
\hline \multicolumn{2}{|l|}{ CYP3A4 substrate } & No & $\begin{array}{c}\text { Yes } \\
\text { (moderate }-18 \%)\end{array}$ & $\begin{array}{c}\text { Yes } \\
\text { (moderate }-25 \%)\end{array}$ & $\begin{array}{c}\text { No } \\
\text { (minimal- } \\
4 \% \text { ) } \\
\end{array}$ & \\
\hline \multicolumn{2}{|l|}{ BCRP substrate } & No & Yes & Yes & No & \\
\hline \multicolumn{2}{|l|}{ OATP1B1 substrate } & No & No & No & Yes & \\
\hline $\begin{array}{l}\text { Oral anti-cancer } \\
\text { agents }\end{array}$ & Metabolic pathway & & & & & $\begin{array}{l}\text { Clinical relevance and } \\
\text { literature data }\end{array}$ \\
\hline \multicolumn{7}{|c|}{ Inhibitors of vascular endothelial growth factor receptor (VEGFR)-associated tyrosine kinases } \\
\hline Axitinib & CYP1A2/2C8 inhibition (in vitro) & & & & & \\
\hline Lenvatinib & No activity on CYP or P-gp & & & & & \\
\hline Pazopanib & Weak inhibitor of CYP3A4/2C8 & & & & & $\begin{array}{l}\text { Monitoring for apixaban and } \\
\text { rivaroxaban toxicity }\end{array}$ \\
\hline Regorafenib & P-gp inhibitor (in vitro) & & & & & \\
\hline Sorafenib & P-gp inhibitor & & & & & Monitoring for DOACs toxicity \\
\hline Sunitinib & P-gp inhibitor & & & & & Monitoring for DOACs toxicity \\
\hline Tivozanib & $\begin{array}{l}\text { Weak inhibitor of CYP2C8 (in vitro) } \\
\text { BCRP inhibitor }\end{array}$ & & & & & $\begin{array}{l}\text { Increased risk of } \\
\text { bleeding (PD interaction) }\end{array}$ \\
\hline \multicolumn{7}{|c|}{ Inhibitor of EGFR-associated tyrosine kinases } \\
\hline Afatinib* & $\begin{array}{l}\text { P-gp inhibitor (moderate) } \\
\text { BCRP inhibitor }\end{array}$ & & & & & $\begin{array}{l}\text { No expected relevant } \\
\text { interaction due to P-gp } \\
\text { pathway } \\
\text { Increased risk of } \\
\text { bleeding (PD interaction) }\end{array}$ \\
\hline Erlotinib* & $\begin{array}{l}\text { CYP3A4/2C8 inhibitor } \\
\text { P-gp inhibitor (strong) } \\
\text { BCRP inhibitor (moderate) }\end{array}$ & & & & & $\begin{array}{l}\text { A case report described } \\
\text { extensive subcutaneous } \\
\text { bleeding with concomitant } \\
\text { use of erlotinib and } \\
\text { dabigatran }\end{array}$ \\
\hline Gefitinib* & $\begin{array}{l}\text { CYP2D6/2C19 inhibitor } \\
\text { P-gp inhibitor (strong) } \\
\text { BCRP inhibitor (strong) }\end{array}$ & & & & & $\begin{array}{l}\text { Potential increase of AUC and } \\
\text { risk of bleeding }\end{array}$ \\
\hline Lapatinib & $\begin{array}{l}\text { Weak inhibitor of intestinal CYP3A4 } \\
\text { P-gp inhibitor }\end{array}$ & & & & & $\begin{array}{l}\text { Potential increase of AUC and } \\
\text { risk of bleeding }\end{array}$ \\
\hline Neratinib & P-gp inhibitor (in vitro) & & & & & Monitoring for DOACs toxicity \\
\hline Osimertinib* & $\begin{array}{l}\text { P-gp inhibitor (in vitro) } \\
\text { BCRP inhibitor (in vitro) }\end{array}$ & & & & & Monitoring for DOACs toxicity \\
\hline \multicolumn{7}{|c|}{ Inhibitors of $B C R-A B L$ tyrosine kinase } \\
\hline Bosutinib & No activity on CYP or P-gp & & & & & $\begin{array}{l}\text { No differences in AUC, } C_{\max } \\
\text { and } T_{\max } \text { between dabigatran } \\
\text { vs dabigatran+bosutinib were } \\
\text { found in a PK study in healthy } \\
\text { volunteers }\end{array}$ \\
\hline Dasatinib & $\begin{array}{l}\text { CYP3A4 inhibitor } \\
\text { (weak) }\end{array}$ & & & & & $\begin{array}{l}\text { Increased risk of } \\
\text { bleeding due to } \\
\text { thrombocytopenic effect and } \\
\text { decreased platelet } \\
\text { aggregation (PD interaction) }\end{array}$ \\
\hline Imatinib & CYP3A4-2C9 inhibition (moderate) & & & & & $\begin{array}{l}\text { Potential increase of AUC and } \\
\text { risk of bleeding }\end{array}$ \\
\hline
\end{tabular}

Additionally, clinicians should be aware that also pharmacodynamic (PD) interactions may result in clinically relevant outcomes, considering that different anticancer agents increase per se the risk of severe bleeding (namely, tivozanib, afatinib, ponatinib, cobimetinib, trametinib, ibrutinib, panobinostat, encorafenib, and binimetinib association); in frail elderly cancer patients exposed to polypharmacotherapy, tight monitoring and risk minimization strategies should be performed, including medication review. Because DOACs do not require $\mathrm{PK} / \mathrm{PD}$ monitoring and there are no biomarkers 
Table 1 (continued)

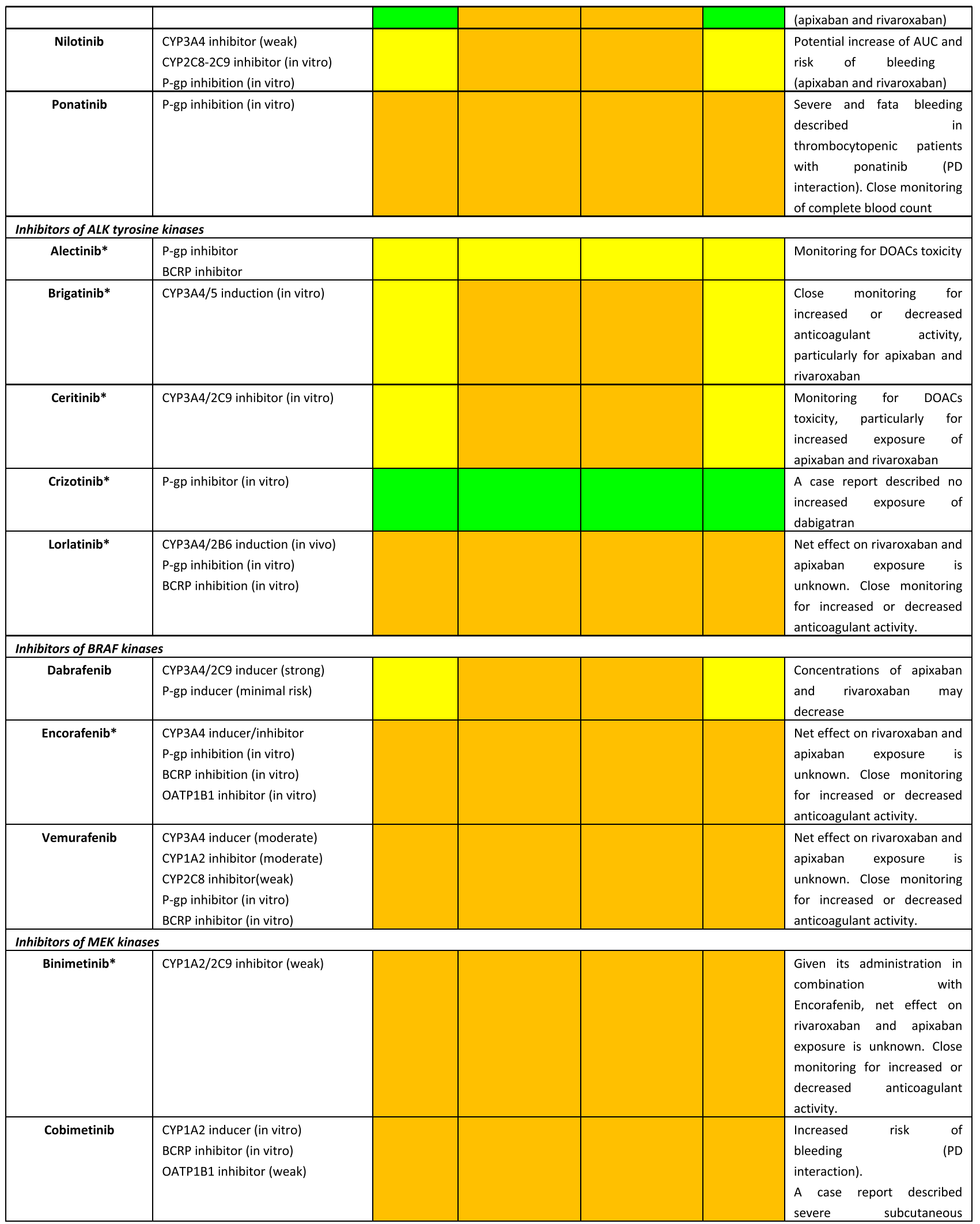


Table 1 (continued)

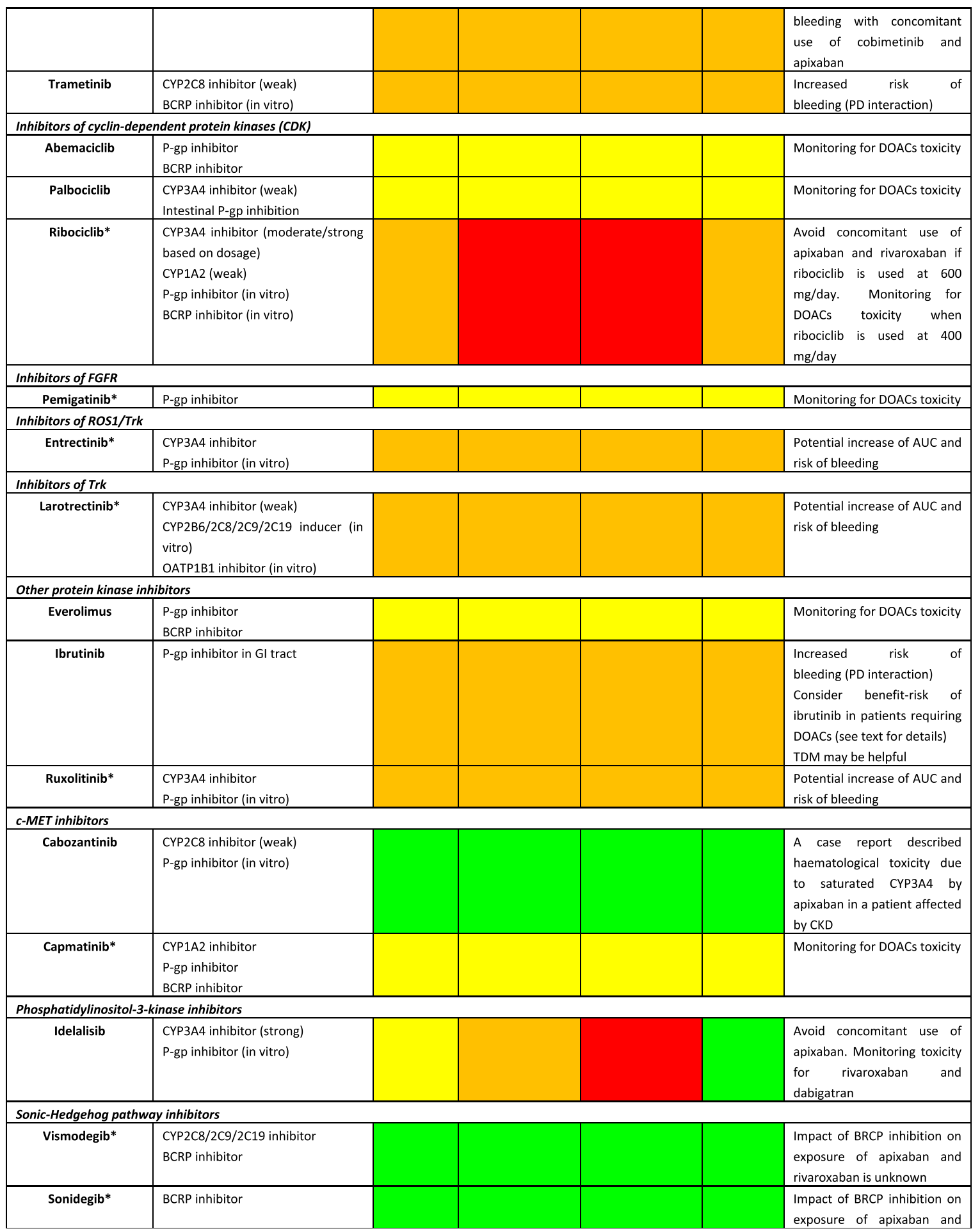

validated in clinical practice, patients should be alerted for early signs of minor bleedings, particularly when several agents (i.e., antibiotics, antiplatelet drugs, and chemotherapy) are concomitantly administered, given the potential synergic or exponential effect on occurrence of relevant DDIs.

\section{Direct Oral Anticoagulants in the Setting of COVID-19 and Cancer: a Double-Edge Sword}

The real impact of polypharmacy and DDIs in frail patients affected by COVID-19 concomitantly treated with novel 
Table 1 (continued)

\begin{tabular}{|c|c|c|}
\hline & & rivaroxaban is unknown \\
\hline \multicolumn{3}{|c|}{ Histone deacetylase (HDAC) inhibitors } \\
\hline Panobinostat & CYP3A4 inhibitor (weak) & $\begin{array}{l}\text { Increased risk of } \\
\text { bleeding due to } \\
\text { thrombocytopenic effect of } \\
\text { panobinostat (PD interaction) }\end{array}$ \\
\hline \multicolumn{3}{|c|}{ Proteasome inhibitors } \\
\hline Ixazomib & No activity on CYP or P-gp & \\
\hline \multicolumn{3}{|c|}{ B-cell lymphoma (BCL)-2 protein inhibitors } \\
\hline Venetoclax & $\begin{array}{l}\text { P-gp inhibition in Gl tract at } \\
\text { therapeutic doses }\end{array}$ & Monitoring for DOACs toxicity \\
\hline \multicolumn{3}{|c|}{ Poly(ADP-ribose) polymerase (PARP) inhibitors } \\
\hline Niraparib & $\begin{array}{l}\text { Weak inhibitor of P-gp (in vitro) } \\
\text { Weak inhibitor of BCRP (in vitro) }\end{array}$ & Monitoring for DOACs toxicity \\
\hline Olaparib & $\begin{array}{l}\text { P-gp inhibitor } \\
\text { BCRP inhibitor (in vitro) }\end{array}$ & $\begin{array}{l}\text { Monitoring for DOACs } \\
\text { toxicity, especially dabigatran } \\
\text { and edoxaban }\end{array}$ \\
\hline Rucaparib & $\begin{array}{l}\text { Weak inhibitor of } \\
\text { CYP3A4/2C9/2C19 } \\
\text { Moderate inhibitor of CYP1A2 } \\
\text { P-gp and BCRP inhibitor (in vitro) }\end{array}$ & $\begin{array}{l}\text { No clinically relevant effect } \\
\text { was observed due to P-gp } \\
\text { inhibitor }\end{array}$ \\
\hline \multicolumn{3}{|c|}{ Hormonal agents - Aromatase inhibitors and anti-androgens } \\
\hline Letrozole* & CYP2A6/2C19 inhibitor (in vitro) & \\
\hline Anastrozole* & $\begin{array}{l}\text { CYP3A4/1A2/2C8/2C9 inhibitor (in } \\
\text { vitro) }\end{array}$ & $\begin{array}{l}\text { Monitoring for DOACs } \\
\text { toxicity, particularly for } \\
\text { increased exposure of } \\
\text { apixaban and rivaroxaban }\end{array}$ \\
\hline Abiraterone & CYP3A4/2C8 inhibitor (weak) & $\begin{array}{l}\text { Monitoring for apixaban } \\
\text { toxicity }\end{array}$ \\
\hline Enzalutamide & $\begin{array}{l}\text { CYP3A4 inducer (strong) } \\
\text { CYP2C9/2C19/1A2 inducer (weak- } \\
\text { moderate) } \\
\text { P-gp inhibitor (in vitro) }\end{array}$ & $\begin{array}{l}\text { Avoid concomitant use of } \\
\text { apixaban and rivaroxaban } \\
\text { due to reduce efficacy. } \\
\text { Monitoring toxicity for } \\
\text { dabigatran and edoxaban }\end{array}$ \\
\hline
\end{tabular}

$C Y P$ cytochrome P450, $P$-g $p$ P-glycoprotein, $B C R P$ breast cancer resistance protein, $A U C$ area under the time-concentration curve, $P D$ pharmacodynamic, $P K$ pharmacokinetic, $T D M$ therapeutic drug monitoring, $C K D$ chronic kidney disease, $D O A C$ direct oral anticoagulant, $D D I$ drug-drug interaction, GI gastrointestinal, OATP1B1 organic anion transporting polypeptide 1B1, $C_{\max }$ peak concentration, $T_{\max }$ time taken to reach peak concentration Red box: avoid co-administration (contraindicated or not recommended). Orange box: potential interaction (caution should be exercised and consider dose adjustment or alternative drugs). Yellow box: potential weak interaction (monitoring for potential underexposure or toxicity). Green box: no interaction expected based on pharmacokinetic properties, although no clinical data exist

DDIs were checked through cancer-druginteractions.org, except for *, where DDIs were predicted on the basis of PK data retrieved from the summary of product characteristics or literature review

anticancer drugs and DOACs represents a current unmet clinical need. In addition to underlying conditions (cancer, AF), direct (i.e., hemostatic abnormalities caused by SARS-CoV-2 [38]) and indirect effects (i.e., intensive care unit $[\mathrm{ICU}]$ admission, deep sedation, mechanical ventilation, and potential prothrombotic action of agents used for the management of the infection) of COVID-19 call for an effective anticoagulation.

Several agents have been proposed for the management of COVID-19, including antivirals (e.g., remdesivir), antibiotics (azithromycin), and immunomodulators/immunosuppressants (e.g., hydroxychloroquine and tocilizumab) [39], although uncertainty about their efficacy in COVID-19 exists. Furthermore, different agents may exhibit PK and/or PD issues when concomitantly administered with DOACs, as reported in Table 2.
Notably, although several studies and case reports [40-47] investigated the impact of ritonavir or tocilizumab on DOAC exposure, none of these was performed in the context of COVID-19. Particularly, the degree of COVID-19 severity and associated renal and/or hepatic injury may increase the likelihood and clinical relevance of DDIs. In this regard, dysregulated immune systems coupled with cytokine storms, mainly involving overproduction of interleukin-6 (IL-6), are important causes of death in severe COVID-19 [48]; thus, tocilizumab and sarilumab, acting as antagonists of the IL-6 receptor, have been proposed for the management of critically ill patients [37, 47]. However, elevated IL-6 levels were found to suppress activities of CYP3A4, CYP2C19, CYP1A2, and P-gp [49,50], and treatment with tocilizumab or sarilumab led to restoration of enzyme activity to non-disease levels $[40,51$, 
Table 2 Key drug interactions and expected toxicities among direct oral anticoagulants and candidate drugs for COVID-19 management. Evidence concerning cardiotoxicity associated with agents used for COVID-19 management is also provided

\begin{tabular}{|c|c|c|c|c|c|c|c|c|}
\hline \multirow{2}{*}{$\begin{array}{l}\text { Agents used for } \\
\text { COVID-19 } \\
\text { management }\end{array}$} & \multirow{2}{*}{$\begin{array}{l}\text { Drug-related } \\
\text { cardiotoxicity }\end{array}$} & \multicolumn{3}{|c|}{ Metabolic pathway } & \multicolumn{4}{|c|}{ DDIs with DOACs } \\
\hline & & $\begin{array}{c}\text { CYP450 } \\
\text { isoenzyme } \\
\text { s activity }\end{array}$ & P-gp & $\begin{array}{c}\text { Other } \\
\text { transporter } \\
\text { s }\end{array}$ & Dabigatran & Rivaroxaban & Apixaban & Edoxaban \\
\hline $\begin{array}{c}\text { Chloroquine } \\
\text { Hydroxychloroquin } \\
\text { e }\end{array}$ & $\begin{array}{c}\text { QT prolongation } \\
++ \\
\text { Cardiomyopath } \\
\qquad+\end{array}$ & $\begin{array}{l}\text { CYP2C8 } \\
\text { inhibitor }\end{array}$ & $\begin{array}{c}\text { Inhibito } \\
r\end{array}$ & - & $\begin{array}{l}\text { Dose might } \\
\text { be reduced }\end{array}$ & $\begin{array}{l}\text { Modest } \\
\text { effect } \\
\text { No dose } \\
\text { reduction }\end{array}$ & $\begin{array}{l}\text { Modest } \\
\text { effect } \\
\text { No dose } \\
\text { reduction }\end{array}$ & $\begin{array}{c}\text { Consider a } \\
\text { dose } \\
\text { reduction } \\
\text { from } 60 \mathrm{mg} \\
\text { to } 30 \mathrm{mg} \\
\text { Monitoring } \\
\text { for bleeding } \\
\text { events }\end{array}$ \\
\hline Lopinavir/Ritonavir & $\begin{array}{c}\text { Myocardial } \\
\text { ischaemia + } \\
\text { Hypertension ++ } \\
\text { Thromboemboli } \\
\text { c events + }\end{array}$ & $\begin{array}{l}\text { CYP3A4 } \\
\text { inhibition } \\
\text { (strong) }\end{array}$ & $\begin{array}{c}\text { Mixed } \\
\text { inducer } \\
/ \\
\text { inhibito } \\
r\end{array}$ & - & $\begin{array}{l}\text { Consider a } \\
\text { dose } \\
\text { reduction } \\
\text { from } 110 \mathrm{mg} \\
\text { to } 75 \mathrm{mg} \\
\text { twice daily in } \\
\text { mild- } \\
\text { moderate } \\
\text { renal } \\
\text { impairment }\end{array}$ & $\begin{array}{l}\text { Increased } \\
\text { bleeding risk } \\
\text { 个AUC } 153 \% \\
\text { 个C } \max 55 \% \\
\text { Combination } \\
\text { should be } \\
\text { avoided }\end{array}$ & $\begin{array}{c}\text { Increased } \\
\text { bleeding risk } \\
\text { Combination } \\
\text { should be } \\
\text { avoided }\end{array}$ & $\begin{array}{c}\text { Consider a } \\
\text { dose } \\
\text { reduction } \\
\text { from } 60 \mathrm{mg} \\
\text { to } 30 \mathrm{mg} \\
\text { Monitoring } \\
\text { for bleeding } \\
\text { events }\end{array}$ \\
\hline Atazanavir & $\begin{array}{c}\text { QT prolongation } \\
+ \\
\text { TdP }+ \\
\text { Hypertension + }\end{array}$ & $\begin{array}{l}\text { CYP3A4 } \\
\text { inhibition } \\
\text { (strong) }\end{array}$ & $\begin{array}{c}\text { Inhibito } \\
r \\
\text { (strong) }\end{array}$ & - & $\begin{array}{l}\text { Increased } \\
\text { bleeding risk } \\
\text { Combination } \\
\text { should be } \\
\text { avoided }\end{array}$ & $\begin{array}{l}\text { Increased } \\
\text { bleeding risk } \\
\text { Combination } \\
\text { should be } \\
\text { avoided }\end{array}$ & $\begin{array}{c}\text { Increased } \\
\text { bleeding risk } \\
\text { Combination } \\
\text { should be } \\
\text { avoided }\end{array}$ & $\begin{array}{c}\text { Consider a } \\
\text { dose } \\
\text { reduction } \\
\text { from } 60 \mathrm{mg} \\
\text { to } 30 \mathrm{mg} \\
\text { Monitoring } \\
\text { for bleeding } \\
\text { events }\end{array}$ \\
\hline Favipiravir & - & $\begin{array}{l}\text { CYP2C8 } \\
\text { inhibitor } \\
\text { (weak) }\end{array}$ & - & - & & & & \\
\hline Interferon- $\boldsymbol{\beta}$ & $\begin{array}{c}\text { Cardiomyopath } \\
\qquad y+ \\
\text { Arrhythmias }+\end{array}$ & $\begin{array}{l}\text { CYP1A2 } \\
\text { inhibitor }\end{array}$ & - & - & & & $\begin{array}{l}\text { CYP1A2 } \\
\text { inhibition } \\
\text { not clinically } \\
\text { relevant for } \\
\text { apixaban }\end{array}$ & \\
\hline Ribavirin & $\begin{array}{l}\text { Tachycardia ++ } \\
\text { Palpitations ++ } \\
\text { Arrhythmias + }\end{array}$ & - & - & - & & & & \\
\hline Remdesivir & $\begin{array}{c}\text { Hypotension } \\
\text { Avoid in } \\
\text { patients treated } \\
\text { with } \\
\text { vasopressors } \\
\text { (Data are } \\
\text { incomplete) }\end{array}$ & $\begin{array}{c}\text { CYP3A4 } \\
\text { inhibitor } \\
\text { (no } \\
\text { significant } \\
\text { effect) } \\
\text { CYP1A2 } \\
\text { inducer }\end{array}$ & - & $\begin{array}{l}\text { OATP1B1- } \\
\text { 1B3 } \\
\text { inhibitor } \\
\text { (in vitro) }\end{array}$ & $\begin{array}{l}\text { No clinically } \\
\text { relevant } \\
\text { impact on } \\
\text { CYP3A4 } \\
\text { due to rapid } \\
\text { remdesivir } \\
\text { clearance } \\
\end{array}$ & $\begin{array}{l}\text { No clinically } \\
\text { relevant } \\
\text { impact on } \\
\text { CYP3A4 } \\
\text { due to rapid } \\
\text { remdesivir } \\
\text { clearance } \\
\end{array}$ & $\begin{array}{l}\text { No clinically } \\
\text { relevant } \\
\text { impact on } \\
\text { CYP3A4 } \\
\text { due to rapid } \\
\text { remdesivir } \\
\text { clearance } \\
\end{array}$ & $\begin{array}{l}\text { No clinically } \\
\text { relevant } \\
\text { impact on } \\
\text { CYP3A4 } \\
\text { due to rapid } \\
\text { remdesivir } \\
\text { clearance } \\
\end{array}$ \\
\hline Tocilizumab & Hypertension ++ & $\begin{array}{l}\text { indirect } \\
\text { effect on } \\
\text { CYP3A4 }\end{array}$ & - & - & & $\begin{array}{l}\text { No a priori } \\
\text { dose } \\
\text { adjustment }\end{array}$ & $\begin{array}{l}\text { No a priori } \\
\text { dose } \\
\text { adjustment }\end{array}$ & \\
\hline
\end{tabular}


Table 2 (continued)

\begin{tabular}{|c|c|c|c|c|c|c|c|c|}
\hline & & $\begin{array}{l}\text { (IL-6 may } \\
\text { inhibit its } \\
\text { activity) }\end{array}$ & & & & $\begin{array}{l}\text { Monitoring } \\
\text { for potential } \\
\text { under- } \\
\text { exposure in } \\
\text { COVID-19 } \\
\text { patients } \\
\text { after } \\
\text { tocilizumab }\end{array}$ & $\begin{array}{l}\text { Monitoring } \\
\text { for potential } \\
\text { under- } \\
\text { exposure in } \\
\text { COVID-19 } \\
\text { patients } \\
\text { after } \\
\text { tocilizumab }\end{array}$ & \\
\hline Sarilumab* & - & $\begin{array}{l}\text { Indirect } \\
\text { effect on } \\
\text { CYP3A4 } \\
\text { (IL-6 may } \\
\text { inhibit its } \\
\text { activity) }\end{array}$ & - & - & & $\begin{array}{l}\text { No a priori } \\
\text { dose } \\
\text { adjustment } \\
\text { Monitoring } \\
\text { for potential } \\
\text { under- } \\
\text { exposure in } \\
\text { COVID-19 } \\
\text { patients } \\
\text { after } \\
\text { sarilumab }\end{array}$ & $\begin{array}{l}\text { No a priori } \\
\text { dose } \\
\text { adjustment } \\
\text { Monitoring } \\
\text { for potential } \\
\text { under- } \\
\text { exposure in } \\
\text { COVID-19 } \\
\text { patients } \\
\text { after } \\
\text { sarilumab }\end{array}$ & \\
\hline Azithromycin* & $\begin{array}{l}\text { Palpitations + } \\
\text { QT prolongation } \\
\text { and TdP } \\
\text { reported }\end{array}$ & $\begin{array}{l}\text { No } \\
\text { significant } \\
\text { effect on } \\
\text { CYP3A4 }\end{array}$ & $\begin{array}{c}\text { P-gp } \\
\text { inhibito } \\
r\end{array}$ & - & $\begin{array}{l}\text { Monitoring } \\
\text { for possible } \\
\text { DOAC } \\
\text { overexposur } \\
\text { e }\end{array}$ & $\begin{array}{l}\text { Monitoring } \\
\text { for possible } \\
\text { DOAC } \\
\text { overexposur } \\
\text { e }\end{array}$ & $\begin{array}{l}\text { Monitoring } \\
\text { for possible } \\
\text { DOAC } \\
\text { overexposur } \\
\text { e }\end{array}$ & $\begin{array}{l}\text { Monitoring } \\
\text { for possible } \\
\text { DOAC } \\
\text { overexposur } \\
\text { e }\end{array}$ \\
\hline
\end{tabular}

$C Y P$ cytochrome P450, $P$ - $g p$ P-glycoprotein, $A U C$ area under the time-concentration curve, $D O A C$ direct oral anticoagulant, $D D I$ drug-drug interaction, OATP1B1 organic anion transporting polypeptide 1B1, $C_{\max }$ peak concentration, TdP torsade de pointes, IL-6 interleukin-6

Red box: avoid co-administration (contraindicated or not recommended). Orange box: potential interaction (caution should be exercised and consider dose adjustment or alternative drugs). Yellow box: potential weak interaction (monitoring for potential underexposure or toxicity). Green box: no interaction expected based on pharmacokinetic properties, although no clinical data exist

DDIs were checked through https://www.covid19-druginteractions.org/, except for *, where DDIs were predicted on the basis of PK data retrieved from the summary of product characteristics or literature review

${ }^{++}$Occurs frequently. ${ }^{+}$Occurs occasionally according to summary of product characteristics

52]. Consequently, caution should be paid in COVID-19 patients treated with IL-6 receptor antagonists and concomitant DOACs (i.e., apixaban or rivaroxaban) and anticancer agents (i.e., ibrutinib, ixazomib, sunitinib, and olaparib) extensively metabolized by CYP3A4, given that unpredictable changes in relevant drug exposure may occur. Furthermore, ritonavir and atazanavir, by virtue of their strong inhibition on CYP3A4 and P-gp, pose several concerns when concomitantly used with DOACs or anticancer agents metabolized through these pathways. Combination should be avoided in order to prevent lifethreatening bleeding caused by anticoagulant overexposure, as recently demonstrated in patients treated with DOACs and lopinavir/ritonavir or darunavir/ritonavir in the COVID19 setting [53].

In consideration of the PK properties of DOACs, the clinical impact of interactions due to the treatment of COVID-19, the possible necessity of ICU admission and mechanical ventilation in severe cases with potential impairment of DOAC absorption, and the requirement for effective anticoagulation, replacing oral anticoagulant therapies with parenteral LMWH or unfractionated heparin was suggested to avoid the risk of over/undertreatment $[53,54,55 \cdot \bullet]$. A dedicated online tool is available for safe prescribing in patients with COVID-19 (https://www.covid19-druginteractions.org/).

\section{Proarrhythmic Liability in Cardio-oncology: the Emerging Case of Atrial Fibrillation by Anticancer Drugs}

The relationship between anticancer therapy and arrhythmias is not well established, and the arrhythmogenic mechanisms remain uncertain as they can be the result of a direct electrophysiological effect or indirect perturbation of cardiac structure and function, including myocardial ischemia and heart failure, which in turn create an arrhythmogenic substrate [56].

Anticancer drug-induced AF is attracting emerging concern and poses diagnostic challenges due to competing factors, including the twofold increased risk of AF by cancer per se and the increased incidence of post-operative AF after pulmonary resection $[57,58]$. Data on iatrogenic $\mathrm{AF}$ are scarce 
and essentially based on non-randomized clinical trials, underpowered, and not sufficiently pragmatic to enroll and characterize real-world patients with cardiovascular risk factors or those having pre-existing cardiac diseases (i.e., highest risk of AF) [59].

A recent pharmacovigilance analysis of WHO VigiBase provided the largest characterization of anticancer druginduced $\mathrm{AF}$ and found 19 agents with significant overreporting. Apart from confirming some widely known associations such as ibrutinib, 9 potentially novel associations were identified especially in hematologic malignancies, including immunomodulating agents (lenalidomide, pomalidomide), kinase inhibitors (nilotinib, ponatinib, and midostaurin), antimetabolites (azacitidine, clofarabine), docetaxel (taxane), and obinutuzumab, with consistent results across sensitivity analyses accounting for potential confounders (e.g., co-reporting of antiarrhythmic drugs and anticoagulants as proxies of pre-existing AF). Considering that anticancer drugs with the strongest associations affect the phosphoinositide 3-kinase/protein kinase B (PI3K/AKT) and mitogen-activated protein kinase (MAPK) signaling pathways, the authors hypothesized these pathways as mostly implicated in AF associated with anticancer drugs, as compared with the "classical" molecular pathway of calcium-handling abnormalities [60]. Clinicians should be aware that risk of AF is also associated with bisphosphonates, mainly zoledronic acid, frequently used in patients with bone metastasis [61].

In this scenario, $\mathrm{AF}$ is generally manageable without anticancer drug discontinuation, to minimize the risk of treatment failure: patients who had ibrutinib interrupted for AF onset had decreased progression-free survival (median 19 months) as compared with those who continued ibrutinib or had dose reductions (median 27 months, $p=0.023$ ) [62]. The use of ibrutinib poses several challenges in cardio-oncology as multiple cardiovascular toxicities were recently described in a pharmacovigilance study using VigiBase, which found overreporting of severe and occasionally fatal cardiac events, including conduction disorders, supraventricular arrhythmias, heart failure, and hemorrhagic events, especially at the central nervous system [63].

Although no randomized clinical trial addressed the rate versus rhythm control strategies in cancer patients experiencing AF associated with anticancer drugs, lessons learned from the management of AF associated with ibrutinib or other drugs can serve as initial guidance [64]: in hemodynamically stable cancer patients with AF related to anticancer drugs, rate control may be preferable to rhythm control because the ability to maintain sinus rhythm after cardioversion may be limited by the continuation of the imputed anticancer drug. Another possibility for rhythm control is AF ablation, especially for patients with impaired left ventricular function. In this subgroup of patients, the CASTLE-AF trial [65] showed improved survival with respect to non-ablation strategy. However, AF ablation in patients with cancer has never been explored due to several issues: efficacy of standard pulmonary vein isolation (in view of possible different mechanisms in cancer patients) and thromboembolic and hemorrhagic risk especially in view of the unpredictable effects of the neoplastic condition on atrial lesions and on effectiveness of standard anticoagulation regimens in both the acute and long-term phases. Theoretically, adoption of cryoablation could provide the best safety margin in view of reduced thrombogenic lesions, although additional confirmation is needed [66]. In a small cohort of 21 cancer survivors undergoing AF ablation [67], the risk of clinically relevant bleedings at 30 days was 3.6 times higher as compared with that of non-cancer patients. This trend remained after propensity score-matched population, and it was independent from the type of anticoagulation. However, enrolled patients had no active cancer treatment and they included a limited number of cancer types (i.e., gastrointestinal, breast, and genitourinary) limiting transferability to other settings. The future evolution of AF ablation through introduction of non-invasive radiosurgery may provide a better approach for sinus rhythm maintenance in cancer patients [68]. Clinicians should be reminded that the decision to use anticoagulants in this setting remains challenging as both CHA2DS2-VASc and HAS-BLED scores were not validated in cancer patients. Moreover, as anticipated, DDI risks should not be overlooked and bleeding risk may be also related to the underlying malignancy, with gastrointestinal cancer more at risk [69].

\section{Proarrhythmic Liability in Cardio-oncology: Focus on QT Prolongation}

Drug-induced QT prolongation is a recognized surrogate marker of cardiotoxicity, potentially leading to the so-called TdP, which may ultimately result in ventricular fibrillation and sudden cardiac death. Drug-induced TdP is still a research and clinical priority in 2020, although the focus shifted from the pre-marketing risk prediction [70] towards the postmarketing real-world setting [71].

The persisting need for bridging the gap between pathophysiological knowledge and clinical practice is demonstrated by the ongoing efforts of Arizona CERT to implement crediblemeds.org, an interactive website devoted to risk assessment of drug-induced QT prolongation [37]. Apart from the widely known section on QT drug lists, the online tool was recently supplemented with several features for healthcare providers [72]: (1) QTFactors.org, listing clinical risk factors associated with QT/TdP risk, also in terms of strength of the evidence (e.g., bradycardia is a strong risk factor for TdP, with high strength of the evidence); (2) OncoSupport, a dedicated printable list of QT-prolonging drugs that are prescribed in patients with cancer, including anticancer agents, antiemetics, antidepressants, and anesthetics, with relevant categorization 
for TdP liability; and (3) MedSafetyScan, a clinical decision support tool specifically released for real-time proarrhythmic risk assessment in the COVID-19 setting (https:// medsafetyscan.org/index.php), offering customized scores depending on the setting (ICU vs. outpatients).

Several targeted anticancer agents such as tyrosine kinase inhibitors (TKIs) are associated with QT liability [73, 74], both via direct effect on ventricular repolarization and through indirect properties, such as heart failure (risk factors per se of TdP). This risk is frequently recognized in the SPCs, in terms of QT prolongation, generic arrhythmia, tachycardia/bradycardia, or indirectly by citing decreased LVEF or myocardial ischemia. Because of the still uncertain causal association, data from spontaneous reporting systems such as the FDA Adverse Event Reporting System (FAERS) should be routinely monitored and update of SPCs is recommended when cases suggesting proarrhythmic risk are increasing (Table 3). This seems for instance the case of axitinib, regorafenib, erlotinib, idelalisib, and venetoclax, for which many cases of AF have been reported in FAERS, without any warning in the relevant SPCs.

These effects may synergize with concomitant medications taken to counteract side effects of chemotherapy (e.g., antinausea) or treat comorbidities (e.g., antidepressants, antimicrobials, loop diuretics, and proton pump inhibitors), with potential PD/ PK interactions (via cytochrome and/or P-gp inhibition), which in turn reduce the cardiac repolarization reserve with increased patients' susceptibility to TdP (Fig. 1). In fact, the prevalence of potential DDIs with anticancer drugs may reach $78 \%$ in the real world [75], especially among targeted therapy, where QT prolongation is a common clinical consequence [76].

The blockade of the so-called hERG channel, which identifies the pore-forming alpha subunit of the rapid component of the delayed rectifier $\mathrm{K}+$ current $(\mathrm{IKr})$, is the most extensively studied and a key mechanism underlying drug-induced QT prolongation, although, at least theoretically, actions on other potassium currents may also account for a prolongation of the action potential duration [77]. Recently, the IKr-based paradigm was challenged by in vivo studies, which pointed out PI3K (alpha isoform in cardiomyocytes) as the major target mediating action potential prolongation by TKIs [78]. Lu et al. [79] described multiple mechanisms underlying action potential prolongation by $\mathrm{PI} 3 \mathrm{Ka}$ inhibition: TKIs reduce IKr and IKs amplitude (which would prolong action potential), while reducing peak calcium and sodium current (expected to shorten the QT interval), thus explaining the arrhythmogenic potential of TKIs without acutely blocking $\mathrm{IKr}$ [80 $]$. This direct interaction with the hERG pharmacophore should rapidly result in QT prolongation, although also delayed onset of proarrhythmia was described with some anticancer drugs such as histone deacetylase (HDAC) inhibitors, which were reported to interfere with hERG channel trafficking [81]. Intriguingly, modifying the degree of selectivity towards HDAC isoforms might be a strategy to develop safer agents in terms of TdP liability: ricolinostat and citarinostat, HDAC6-selective inhibitors, theoretically possess better cardiac tolerability as compared with pan-HDAC inhibitors [82].

\section{Risk Stratification for Torsadogenicity: Myth or Reality?}

According to crediblemeds.org, vandetanib, arsenic trioxide, aclarubicin, cesium chloride, and oxaliplatin are considered to carry torsadogenic risk in humans even when used as recommended, whereas several TKIs (e.g., osimertinib) are classified as "possible risk of TdP"; they can cause QT prolongation but there is insufficient evidence that these drugs, when used as directed in official labeling, are associated with a risk of TdP. Supportive medications with TdP proclivity are represented by ondansetron and domperidone and selective serotonin re-uptake inhibitors such as citalopram.

The critical challenge in all these scenarios is to identify safer therapeutic alternatives, for which clinical experience remains a crucial determinant. In fact, there is still ongoing debate on whether or not QT prolongation and TdP risk should be considered a class effect or peculiarities exist when prescribing within the same pharmacological class.

The case of TKIs that target the epidermal growth factor receptor (EGFR) is paradigmatic: apart from slight $\mathrm{PK}$ differences (with CYP3A4 being the main enzyme involved in the metabolism for a number of TKIs-EGFR), diarrhea should be considered a class effect of these drugs and may predispose to dehydration and hypokalemia, thus increasing the likelihood of TdP. Of note, hypomagnesemia appears to be a specific safety issue of osimertinib (occurring in up to $30 \%$ of patients), which may partially explain the higher frequency of post-marketing reports as compared with that of other antiEGFR agents [83].

Diarrhea, nausea, and vomiting, which increase TdP susceptibility, are relatively common safety issues observed with different targeted agents, including with anaplastic lymphoma kinase (ALK) TKIs [84] and P13K inhibitors. Hepatocyte growth factor receptor (c-MET) inhibitors have a complex tolerability profile, with multiple mechanisms likely to result in proarrhythmia, including direct QT-prolonging effect (albeit rare), cardiac failure (rare instances especially described in the post-marketing setting), and dose-dependent symptomatic bradycardia (i.e., syncope, dizziness, and hypotension), especially with crizotinib observed in $2.4 \%$ of patients across clinical trials, and potentially developing after several weeks of drug initiation [85]. HDAC inhibitors are also expected to cause clinically significant QT prolongation although drugspecific peculiarities were observed in drug development and dedicated thorough QT studies were not systematically performed [86]. Among PI3K inhibitors, QT prolongation appears to be specific with copanlisib (intravenously 
Table 3 Cardiotoxicity of different oral anticancer agents according to the summary of product characteristics and adverse reactions retrieved from the US Food and Drug Administration Adverse Event Reporting System (FAERS)*

\begin{tabular}{|c|c|c|c|c|c|}
\hline Oral & Cardiotoxicity & & & & Vascular \\
\hline agen & $\begin{array}{l}\text { Decreased Arrhythmias } \\
\text { LVEF }\end{array}$ & $\begin{array}{l}\text { QT } \\
\text { prolonged }\end{array}$ & $\begin{array}{l}\text { Myocardial } \\
\text { ischemia }\end{array}$ & $\begin{array}{l}\text { Bradycardia } \\
\text { Tachycardia }\end{array}$ & \\
\hline
\end{tabular}

\section{FAERS data}

Overall Arrhythmic Predisposing events AEs events

AF $\quad$ QT $\uparrow$ TdP Diarrhea Vomiting

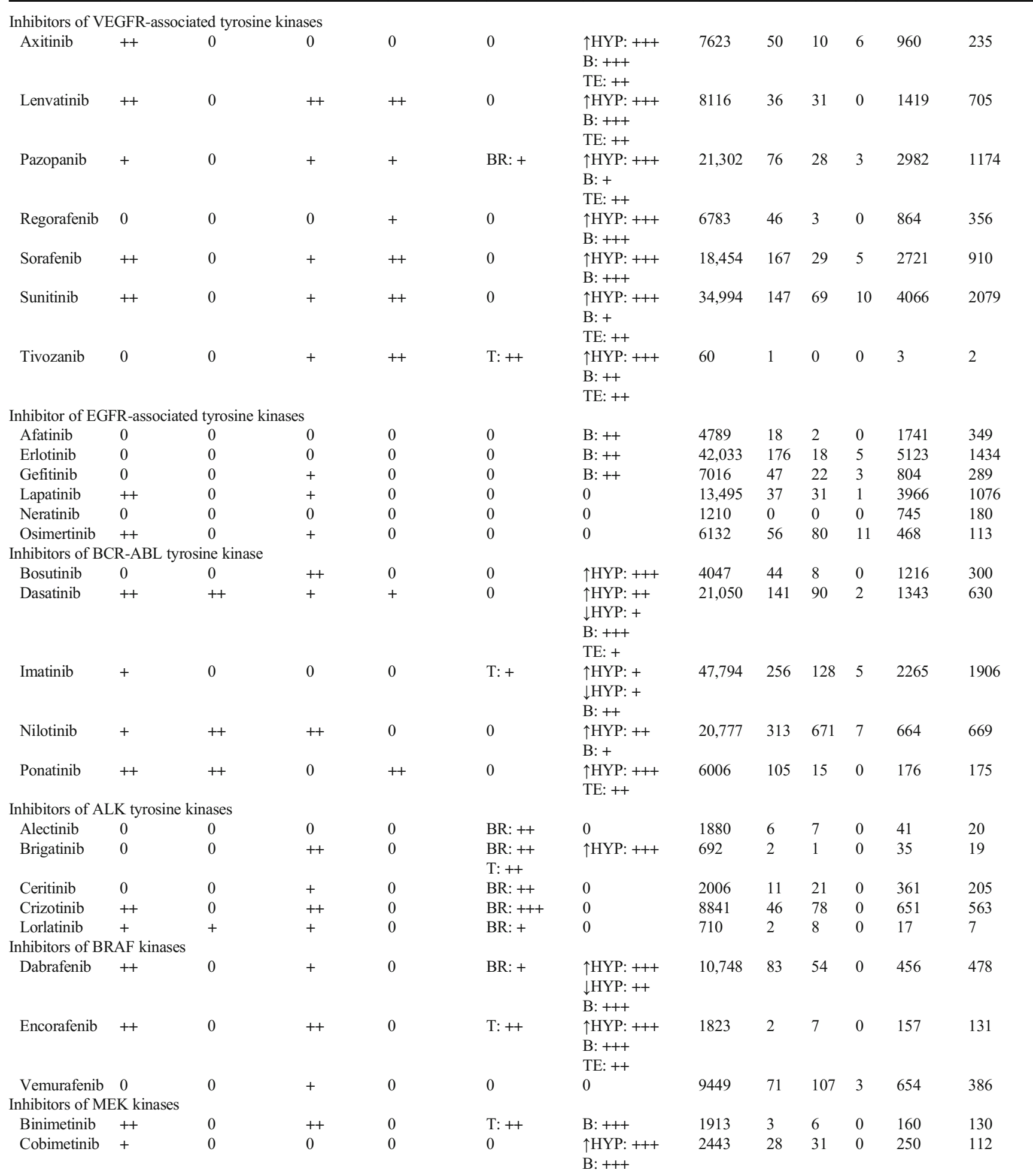


Table 3 (continued)

\begin{tabular}{|c|c|c|c|c|c|c|c|c|c|c|c|c|}
\hline \multirow{3}{*}{$\begin{array}{l}\text { Oral } \\
\text { anticancer } \\
\text { agent }\end{array}$} & \multicolumn{5}{|c|}{ Cardiotoxicity } & \multirow{3}{*}{$\begin{array}{l}\text { Vascular } \\
\text { events }\end{array}$} & \multicolumn{6}{|c|}{ FAERS data } \\
\hline & \multirow[t]{2}{*}{$\begin{array}{l}\text { Decreased } \\
\text { LVEF }\end{array}$} & \multirow[t]{2}{*}{ Arrhythmias } & \multirow[t]{2}{*}{$\begin{array}{l}\text { QT } \\
\text { prolonged }\end{array}$} & \multirow[t]{2}{*}{$\begin{array}{l}\text { Myocardial } \\
\text { ischemia }\end{array}$} & \multirow[t]{2}{*}{$\begin{array}{l}\text { Bradycardia } \\
\text { Tachycardia }\end{array}$} & & \multirow[t]{2}{*}{$\begin{array}{l}\text { Overall } \\
\text { AEs }\end{array}$} & \multicolumn{3}{|c|}{$\begin{array}{l}\text { Arrhythmic } \\
\text { events }\end{array}$} & \multicolumn{2}{|c|}{ Predisposing event } \\
\hline & & & & & & & & $\mathrm{AF}$ & $\mathrm{QT} \uparrow$ & $\mathrm{TdP}$ & Diarrhea & Vomiting \\
\hline Trametinib & ++ & 0 & 0 & 0 & BR: ++ & $\begin{array}{l}\uparrow \text { HYP: }+++ \\
\downarrow \text { HYP: ++ } \\
\text { B: +++ } \\
\text { TE: }+\end{array}$ & 11,437 & 84 & 45 & 0 & 557 & 491 \\
\hline \multicolumn{13}{|c|}{ Inhibitors of cyclin-dependent protein kinases (CDK) } \\
\hline Abemaciclib & 0 & 0 & 0 & 0 & 0 & TE: ++ & 3062 & 16 & 0 & 0 & 912 & 201 \\
\hline Palbociclib & 0 & 0 & 0 & 0 & 0 & 0 & 39,646 & 97 & 52 & 1 & 2363 & 1396 \\
\hline Ribociclib & 0 & 0 & ++ & 0 & 0 & 0 & 5210 & 64 & 252 & 1 & 315 & 300 \\
\hline \multicolumn{13}{|c|}{ Inhibitors of FGFR } \\
\hline Pemigatinib & 0 & 0 & 0 & 0 & 0 & 0 & 3 & 0 & 0 & 0 & 0 & 1 \\
\hline \multicolumn{13}{|c|}{ Inhibitors of ROS1/Trk } \\
\hline \multicolumn{13}{|c|}{ Inhibitors of Trk } \\
\hline Larotrectinib & 0 & 0 & 0 & 0 & 0 & 0 & 129 & 1 & 0 & 0 & 4 & 3 \\
\hline \multicolumn{13}{|c|}{ Other protein kinase inhibitors } \\
\hline Everolimus & 0 & 0 & 0 & 0 & 0 & $\begin{array}{l}\uparrow \mathrm{HYP}:+++ \\
\text { B: }++\end{array}$ & 35,421 & 154 & 31 & 1 & 2755 & 1497 \\
\hline Ibrutinib & 0 & ++ & 0 & 0 & 0 & $\begin{array}{l}\uparrow H Y P:+++ \\
\text { B: +++ }\end{array}$ & 32,166 & 1809 & 12 & 6 & 2183 & 572 \\
\hline Ruxolitinib & 0 & ++ & 0 & 0 & 0 & $\begin{array}{l}\uparrow H Y P:+++ \\
\text { B: +++ }\end{array}$ & 33,401 & 208 & 10 & 0 & 1454 & 665 \\
\hline \multicolumn{13}{|c|}{ c-MET inhibitors } \\
\hline Cabozantinib & 0 & 0 & + & + & 0 & $\begin{array}{l}\uparrow \mathrm{HYP}:+++ \\
\text { B: }+ \\
\text { TE: ++ }\end{array}$ & 13,603 & 54 & 8 & 0 & 2686 & 677 \\
\hline Capmatinib & 0 & 0 & 0 & 0 & 0 & 0 & 19 & 1 & 0 & 0 & 0 & 0 \\
\hline \multicolumn{13}{|c|}{ Phosphatidylinositol-3-kinase inhibitors } \\
\hline Idelalisib & 0 & 0 & 0 & 0 & 0 & 0 & 5909 & 90 & 0 & 0 & 706 & 160 \\
\hline \multicolumn{13}{|c|}{ Sonic hedgehog pathway inhibitors } \\
\hline Vismodegib & 0 & 0 & 0 & 0 & 0 & 0 & 4904 & 11 & 1 & 0 & 274 & 168 \\
\hline Sonidegib & 0 & 0 & 0 & 0 & 0 & 0 & 261 & 3 & 0 & 0 & 12 & 11 \\
\hline \multicolumn{13}{|c|}{ Histone deacetylase (HDAC) inhibitors } \\
\hline Panobinostat & 0 & ++ & ++ & + & 0 & $\begin{array}{l}\uparrow \text { HYP: }++ \\
\downarrow \text { HYP: }+++ \\
\text { B: }++\end{array}$ & 1610 & 31 & 21 & 0 & 341 & 104 \\
\hline \multicolumn{13}{|c|}{ Proteasome inhibitors } \\
\hline Ixazomib & 0 & 0 & 0 & 0 & 0 & TE: + & 10,482 & 61 & 3 & 0 & 1095 & 430 \\
\hline \multicolumn{13}{|c|}{ B cell lymphoma (BCL)-2 protein inhibitors } \\
\hline Venetoclax & 0 & 0 & 0 & 0 & 0 & 0 & 12,767 & 218 & 5 & 0 & 523 & 213 \\
\hline Poly(ADP-ribos & e) polymerase & (PARP) inhibi & tors & & & & & & & & & \\
\hline Niraparib & 0 & 0 & 0 & 0 & $\mathrm{~T}:++$ & $\uparrow$ HYP: +++ & 6475 & 49 & 3 & 0 & 422 & 777 \\
\hline Olaparib & 0 & 0 & 0 & 0 & 0 & 0 & 4327 & 13 & 3 & 0 & 156 & 243 \\
\hline Rucaparib & 0 & 0 & 0 & 0 & 0 & 0 & 4887 & 11 & 2 & 0 & 511 & 524 \\
\hline Hormonal agent & s: aromatase i & nhibitors and an & atiandrogens & & & & & & & & & \\
\hline Letrozole & ++ & ++ & 0 & + & $\mathrm{T}:+$ & $\begin{array}{l}\uparrow \text { HYP: +++ } \\
\text { TE: }+\end{array}$ & 17,376 & 179 & 156 & 1 & 874 & 618 \\
\hline Anastrozole & 0 & 0 & 0 & ++ & 0 & TE: ++ & 14,877 & 88 & 12 & 1 & 433 & 255 \\
\hline Abiraterone & ++ & ++ & + & + & $\mathrm{T}:++$ & 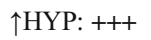 & 22,018 & 190 & 30 & 7 & 468 & 367 \\
\hline Enzalutamide & 0 & 0 & + & ++ & 0 & ^HYP: +++ & 42,170 & 197 & 47 & 1 & 2259 & 1012 \\
\hline
\end{tabular}

$T E$ thromboembolic events, $B$ bleeding, $\uparrow H Y P$ hypertension, $\downarrow H Y P$ hypotension, $B R$ bradycardia, $T$ tachycardia, $Q T \uparrow$ QT prolonged, $T d P$ torsade de pointes, $A F$ atrial fibrillation

*Data retrieved querying the public dashboard of the FDA adverse reporting system (FAERS; https://www.fda.gov/drugs/questions-and-answers-fdasadverse-event-reportingsystem-faers/fda-adverse-event-reporting-system-faers-publicdashboard, searches performed on 14/05/2020; data as of March 31, 2020). It is important to quickly address limitations of this analysis, including data quality (potential existence of pre-marketing reports, duplicates, and missing information), the likelihood of underreporting, the potential influence of external factors (time on the market and media attention), the lack of exposure data (drug prescription/consumption), and the inability to establish firm causality, incidence, risk assessment, and risk ranking which cannot be provided. These data only provide a general picture of the current arrhythmic reporting pattern with novel oral anticancer agents

${ }^{+++}$Occurs very frequently. ${ }^{++}$Occurs frequently. ${ }^{+}$Occurs occasionally. 0 not reported (according to the summary of product characteristics) 


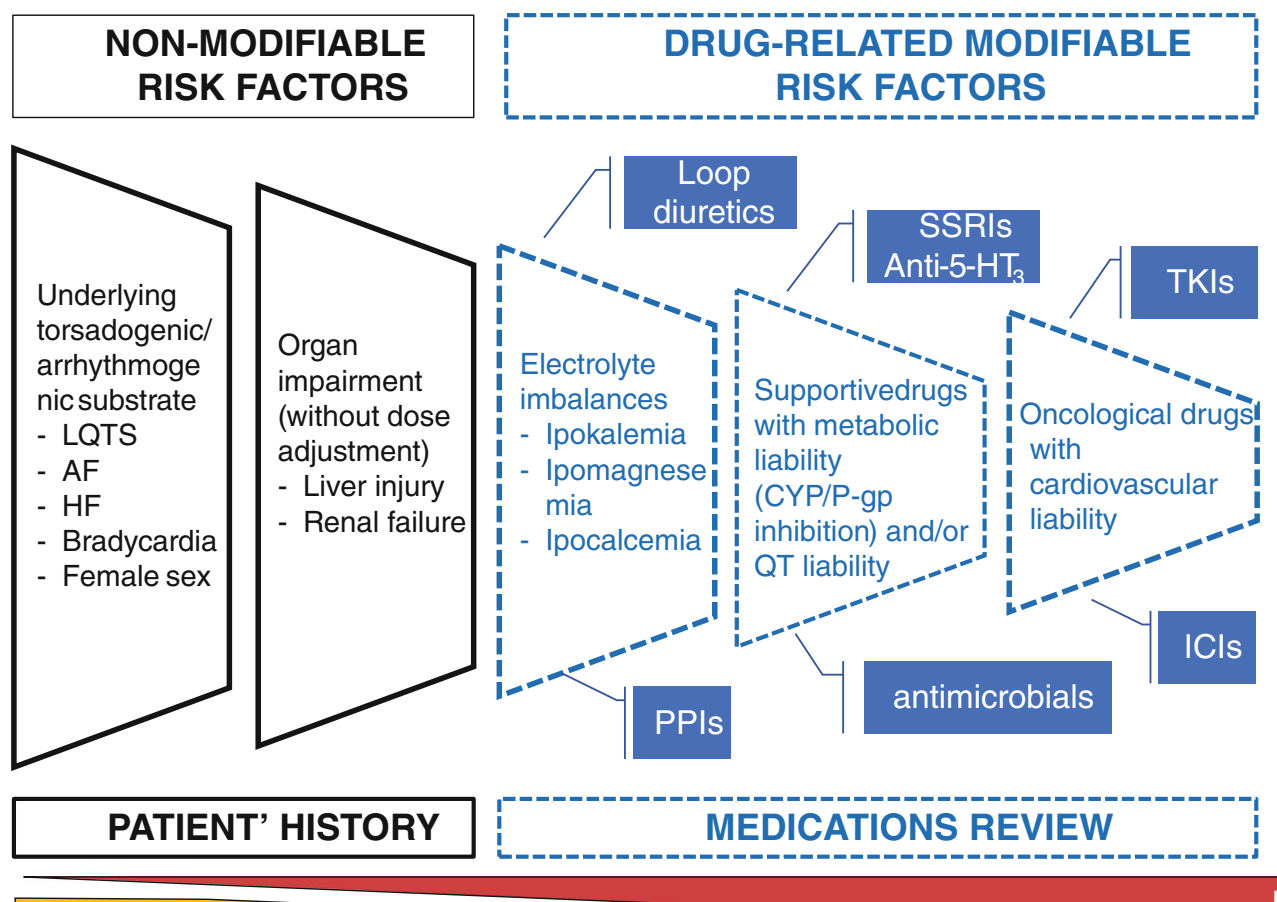

Repolarization Reserve

Inflammation in COVID-19

Fig. 1 Revisiting the concept of the reduced repolarization reserve in cardio-oncology during the COVID-19 era. ACovCS, acute COVID cardiovascular syndrome; ICIs, immune checkpoint inhibitors; PPIs, proton pump inhibitors; SSRIs, selective serotonin re-uptake inhibitors; TKIs, tyrosine kinase inhibitors; LQTS, long QT syndrome; AF, atrial fibrillation; HF, heart failure; ECG, Electrocardiography administered), and a post-marketing study was committed by regulators to determine the proarrhythmic effect in subjects with advanced solid tumors and non-Hodgkin's lymphoma [24]. Notably, unexpected reports of AF with idelalisib have been recently recorded in the EudraVigilance database, although their significance is unclear. Interestingly, ibrutinib (another small-molecule agent used to treat B cell lymphomas and leukemias) and idelalisib share a number of common safety issues [87]. Also, drugs targeting the hedgehog pathway are differently associated with QT prolongation, with arsenic trioxide carrying the highest risk, whereas vismodegib and sonidegib (inhibitors of Smoothened) do not appear to directly affect the QT interval, although diarrhea, nausea, and vomiting should not be overlooked as risk factors [88]. Cyclin-dependent kinase (CDK) 4/6 inhibitors and poly(ADP-ribose) polymerase (PARP) inhibitors are relatively new classes of anticancer drugs for which the evidence on proarrhythmic risk is still provisional, although QT prolongation was preferentially linked to ribociclib, and rucaparib was recently added in the list of drugs with "possible risk of TdP."

In summary, QT prolongation should be taken as a class effect by the majority of anticancer drugs through direct or indirect mechanisms: direct hERG blockade/interference, P13K inhibition, $\mathrm{PK}$ interactions mediated by metabolic liability (CYP substrate/inhibition), and indirect PD effects (diarrhea, vomiting resulting in clinically important electrolyte imbalances such as hypokalemia and hypomagnesemia). However, the actual risk of TdP occurrence should be assessed in the individual patient and depends on the presence of multiple drug- and host-related risk factors, some of which are modifiable and minimized. Notably, post-marketing data presented in Table 3 suggested that $\mathrm{TdP}$ is only rarely reported with targeted anticancer drugs, as compared with QT prolongation, although the recent marketing approval of several agents and the likelihood of underreporting call for continuous pharmacovigilance monitoring, also in the light of high reporting of diarrhea and vomiting.

Therefore, as a general rule, electrocardiogram (ECG) represents an inexpensive, non-invasive monitoring tool to early recognize $\mathrm{TdP}$ and potentially prevent its occurrence through QT measurement, although a remarkable underuse was recently documented in oncology patients receiving QT-prolonging drugs [89]. Notably, we previously reported the results of a prolonged prospective ECG follow-up in a cohort of outpatients initiating chemotherapy in a university center specialized in female cancer. Enrolled patients were followed for 992 chemotherapy cycles (median 7; interquartile range 6-13). No cumulative effect on QTc prolongation nor a relevant effect of prophylactic/supportive drugs emerged. More interestingly, we defined a novel parameter, the baseline-first chemotherapy averaged QTc, based on measurement on baseline QTc and QTc after the 1st 
chemotherapy administration able to identify $100 \%$ of patients with Max-QTe>500 ms and 96\% with MaxQTc 481-500 ms during all the follow-up, independently to the type and number of chemotherapy regimens received [90]. This kind of approach should be further explored to identify the most cost-effective monitoring regimen for ECG monitoring in cancer patients.

\section{Torsadogenic Liability in Cardio-oncology: Focus on Patients With COVID-19 Infection}

While our epidemiological knowledge about COVID-19 is rapidly evolving, emerging data are largely concordant in pointing out a systemic disease involving the liver, kidney, respiratory, inflammatory, immune, and cardiovascular system. The spectrum of the so-called acute COVID-19 cardiovascular syndrome encompasses a variety of manifestations, including coronary syndrome, myocardial injury without coronary artery disease, arrhythmias, thromboembolic complications, pericardial effusion, and de novo systolic dysfunction, with myocarditis/myopericarditis, cytokine storm, and stressinduced cardiomyopathy likely to be leading etiological factors of the proarrhythmic liability [91, 92]. Currently, a trial investigating the efficacy of early acute coronary syndrome therapy (including rivaroxaban) in preventing cardiac complication of COVID-19 disease is ongoing (Clinicaltrials.gov: NCT04333407).

Although it is currently believed that myocardial damage might represent a main driver of enhanced arrhythmic risk in COVID-19 patients, underlying mechanisms are still under investigation. Two main actors are likely to contribute: concomitant pharmacological treatments and high-grade systemic inflammatory state [93]. In cardio-oncology, these COVID-19 proarrhythmic factors may synergize with pre-existing arrhythmogenic substrates to reduce the repolarization reserve in the myocardium, with ultimate TdP onset (Fig. 1).

Different agents are used "off-label" to counteract virus invasion/replication and may promote QT prolongation. This is especially the case of chloroquine/hydroxychloroquine and lopinavir/ritonavir, which can impact ventricular repolarization via direct ( $\mathrm{hERG}$ blockade) and indirect mechanisms (inhibition of CYP2D6 and CYP3A4, respectively). Of note, chloroquine/ hydroxychloroquine has unique pharmacokinetics (no large impact of renal dysfunction, critical illness, or obesity is expected, although in critically ill patients, drug absorption might be hampered) and possesses multifunctional pharmacodynamic properties, including direct myocardial toxicity and bradycardia by modulating the hyperpolarization-activated current (If) [94]. Of note, the prophylactic use of chloroquine/hydroxychloroquine in predominantly healthy, asymptomatic healthcare workers, coupled with feasibility issues in performing ECG in the outof-hospital setting, and the frequent combination with azithromycin (a potential QT-prolonging agent with in vitro activity against COVID-19) may further increase the likelihood of TdP occurrence, especially in subjects with unknown congenital long QT syndrome [95-97].

Fighting systemic inflammation in COVID-19 patients represents a promising therapeutic strategy in COVID-19, especially in severe cases. The so-called inflammatory cardiac channelopathies were described, as IL-6 was demonstrated to directly inhibit the hERG channel [98]. Moreover, inflammatory cytokines can induce cardiac sympathetic system hyperactivation, via the central hypothalamus-mediated (inflammatory reflex) and peripheral (left stellate ganglia activation) pathways [99], potentially resulting in arrhythmias especially in patients with inherited long QT syndrome. As anticipated, IL-6 inhibits CYP3A4, thereby modifying PK of several medications, including QT-prolonging drugs. Therefore, it seems rational to target inflammatory response to reduce cardiovascular complications and relevant arrhythmic events: tocilizumab causes rapid and significant QT shortening, with relevant decreases in cytokine and C-reactive protein levels [100]. In this perspective, it is interesting to recall the results of the Canakinumab Antiinflammatory Thrombosis Outcome Study (CANTOS) trial [101]. In this study, the human monoclonal anti-human interleukin-1 beta antibody, canakinumab, reduced the rate of recurrent cardiovascular events in patients with previous myocardial infarction. Intriguingly, additional analyses revealed a dosedependent trend towards reduction of hospitalization for heart failure (independent of prior history) and a lower risk of incident lung cancer. Notably, recent studies showed that IL-1 $\beta$ might have electrophysiological effects changing $\mathrm{Ca}^{2+}$ handling and cell-cell connection, being associated with the prolonged QTc interval and presence of AF, with preliminary results on protective effects on post-infarction patients [102, 103].

In this intricate scenario, there is no consensus on optimal management to mitigate the underlying torsadogenic substrate. Different guidelines and authors have proposed recommendations for QT monitoring [104-107]: although there is general agreement on the need for baseline QT assessment and general discontinuation rules (e.g., QT interval, corrected for cardiac frequency, $>500 \mathrm{~ms}$, and increases $>60 \mathrm{~ms}$ ), the timing for electrocardiographic re-assessment and re-check may vary depending on the drug (e.g., after 3-4 days of therapy initiation with hydroxychloroquine/azithromycin), as well as underlying expected susceptibility (e.g., in patients with borderline QT and structural heart disease, telemetry should be considered, also with wearable devices for out-of-hospital monitoring). Notwithstanding practicalities in carrying out home monitoring, timely correction of electrolyte imbalances before prescribing QT-prolonging agents (and monitoring relevant blood levels) is recommended, although it is unclear whether an empirical approach through preventive administration of potassium and magnesium is actually effective in mitigating the risk of TdP occurrence. 
In summary, the burden of arrhythmogenicity in COVID-19 can be mitigated by optimizing concomitant pharmacotherapies: in the acute viral phase, medication review and cardiovascular monitoring remain cornerstones for safe prescribing especially in patients exposed to multiple QT-prolonging drugs, including anticancer drugs, whereas in the later systemic phase, IL-6 targeted therapies (tocilizumab and sarilumab, under investigation in clinical trials) can promote the recovery from multiorgan dysfunction although the actual impact on the (high) proarrhythmic risk remains unclear.

\section{Conclusion}

The rapidly evolving spectrum of cardiovascular manifestations with novel targeted therapy poses new diagnostic and therapeutic challenges for oncologists and cardiologists, who must be aware of clinical pharmacology to identify clinically relevant DDIs. Considering the increasing use of DOACs in oncology, and the large number of anticancer drugs inhibiting the activity of CYP34 and/or P-gp predicted DDIs can result in overexposure to DOACs (for which no PK/PD monitoring is still required), thus increasing the risk of bleeding. The paucity of real-world data supports the need for active pharmacovigilance and pharmacoepidemiological research, especially for apixaban and rivaroxaban (partly metabolized by CYP3A4), as well as edoxaban, the latest approved DOAC.

Moreover, oncological patients are vulnerable to proarrhythmias, mainly due to multiple QT-prolonging agents, especially in patients with COVID-19, who frequently receive drugs with torsadogenic liability. These high-risk individuals should be prioritized to target preventive strategies, including optimal antithrombotic management, medication review, correction of electrolyte imbalances, and stringent ECG monitoring. Critical assessment of public online tools, including SPCs, is also crucial for safe prescribing.

Funding Open access funding provided by Alma Mater Studiorum Università di Bologna within the CRUI-CARE Agreement.

\section{Compliance with Ethical Standards}

Conflict of Interest AA reports fees for advisory board participation from Roche, Merck Sharp \& Dohme, AstraZeneca, and Bristol Myers Squibb and research grants for spontaneous studies from Roche and Bristol Myers Squibb, all outside the scope of the present paper. ER reports personal fee from Novartis, outside the submitted work. ID reports minor speaker fees from Daiichi Sankyo, Boehringer Ingelheim, Pfizer, and Bayer, outside the submitted work.

Human and Animal Rights and Informed Consent This article does not contain any studies with human or animal subjects performed by any of the authors.
Ethics Approval Not available.

Open Access This article is licensed under a Creative Commons Attribution 4.0 International License, which permits use, sharing, adaptation, distribution and reproduction in any medium or format, as long as you give appropriate credit to the original author(s) and the source, provide a link to the Creative Commons licence, and indicate if changes were made. The images or other third party material in this article are included in the article's Creative Commons licence, unless indicated otherwise in a credit line to the material. If material is not included in the article's Creative Commons licence and your intended use is not permitted by statutory regulation or exceeds the permitted use, you will need to obtain permission directly from the copyright holder. To view a copy of this licence, visit http://creativecommons.org/licenses/by/4.0/.

\section{References}

Papers of particular interest, published recently, have been highlighted as:

- Of importance

•- Of major importance

1.• Zamorano JL, Lancellotti P, Rodriguez Muñoz D, Aboyans V, Asteggiano R, Galderisi M, et al. 2016 ESC Position Paper on cancer treatments and cardiovascular toxicity developed under the auspices of the ESC Committee for Practice Guidelines: The Task Force for cancer treatments and cardiovascular toxicity of the European Society of Cardiology (ESC). Eur Heart J. 2016;37(36):2768-801 The first position paper on cardiovascular toxicities with anticancer drugs.

2. Raschi E, Diemberger I, Cosmi B, De Ponti F. ESC position paper on cardiovascular toxicity of cancer treatments: challenges and expectations-authors' reply. Intern Emerg Med. 2018;13(4):6356.

3. Raschi E, Vasina V, Ursino MG, Boriani G, Martoni A, De Ponti F. Anticancer drugs and cardiotoxicity: insights and perspectives in the era of targeted therapy. Pharmacol Ther. 2010;125(2):196218.

4. Raschi E, De Ponti F. Cardiovascular toxicity of anticancertargeted therapy: emerging issues in the era of cardio-oncology. Intern Emerg Med. 2012;7(2):113-31.

5. Herrmann J. Adverse cardiac effects of cancer therapies: cardiotoxicity and arrhythmia. Nat Rev Cardiol. 2020;17:474 502. https://doi.org/10.1038/s41569-020-0348-1.

6. Herrmann J. Vascular toxic effects of cancer therapies. Nat Rev Cardiol. 2020;17:503-22. https://doi.org/10.1038/s41569-0200347-2.

7. Melloni C, Shrader P, Carver J, Piccini JP, Thomas L, Fonarow $\mathrm{GC}$, et al. Management and outcomes of patients with atrial fibrillation and a history of cancer: the ORBIT-AF registry. Eur Heart J Qual Care Clin Outcomes. 2017;3(3):192-7.

8. Ostenfeld EB, Erichsen R, Pedersen L, Farkas DK, Weiss NS, Sørensen HT. Atrial fibrillation as a marker of occult cancer. PLoS One. 2014;9(8):e102861.

9. Hu YF, Liu CJ, Chang PM, Tsao HM, Lin YJ, Chang SL, et al. Incident thromboembolism and heart failure associated with newonset atrial fibrillation in cancer patients. Int $\mathrm{J}$ Cardiol. 2013;165(2):355-7.

10. Conen D, Wong JA, Sandhu RK, Cook NR, Lee I-M, Buring JE, et al. Risk of malignant cancer among women with new-onset atrial fibrillation. JAMA Cardiol. 2016;1(4):389-96. 
11. Melloni C, Dunning A, Granger CB, Thomas L, Khouri MG, Garcia DA, et al. Efficacy and safety of apixaban versus warfarin in patients with atrial fibrillation and a history of cancer: insights from the ARISTOTLE trial. Am J Med. 2017;130(12):14401448.e1.

12. Chen ST, Hellkamp AS, Becker RC, Berkowitz SD, Breithardt G, Fox KAA, et al. Efficacy and safety of rivaroxaban vs. warfarin in patients with non-valvular atrial fibrillation and a history of cancer: observations from ROCKET AF. Eur Heart J Qual Care Clin Outcomes. 2019;5(2):145-52.

13. Fanola CL, Ruff CT, Murphy SA, Jin J, Duggal A, Babilonia NA, et al. Efficacy and safety of edoxaban in patients with active malignancy and atrial fibrillation: analysis of the ENGAGE AF TIMI 48 trial. J Am Heart Assoc. 2018;7(16):e008987.

14. D'Souza M, Carlson N, Fosbøl E, Lamberts M, Smedegaard L, Nielsen D, et al. CHA2DS2-VASc score and risk of thromboembolism and bleeding in patients with atrial fibrillation and recent cancer. Eur J Prev Cardiol. 2018;25(6):651-8.

15. Patell R, Gutierrez A, Rybicki L, Khorana AA. Usefulness of CHADS2 and CHA2DS2-VASc scores for stroke prediction in patients with cancer and atrial fibrillation. Am J Cardiol. 2017;120(12):2182-6.

16. Lee AY, Levine MN, Baker RI, Bowden C, Kakkar AK, Prins M, et al. Randomized comparison of low-molecular-weight heparin versus oral anticoagulant therapy for the prevention of recurrent venous thromboembolism in patients with cancer (CLOT) investigators. Low-molecular-weight heparin versus a coumarin for the prevention of recurrent venous thromboembolism in patients with cancer. N Engl J Med. 2003;349(2):146-53.

17.• Steffel J, Verhamme P, Potpara TS, Albaladejo P, Antz M, Desteghe L, et al. The 2018 European Heart Rhythm Association Practical Guide on the use of non-vitamin K antagonist oral anticoagulants in patients with atrial fibrillation. Eur Heart J. 2018;39(16):1330-93 The updated EHRA guideline specifically devoted to the use of DOACs, including the issue of drug interactions.

18. Launay-Vacher V, Oudard S, Janus N, Gligorov J, Pourrat X, Rixe $\mathrm{O}$, et al. Prevalence of renal insufficiency in cancer patients and implications for anticancer drug management: the renal insufficiency and anticancer medications (IRMA) study. Cancer. 2007;110(6):1376-84.

19. Horie S, Oya M, Nangaku M, Yasuda Y, Komatsu Y, Yanagita M, et al. Guidelines for treatment of renal injury during cancer chemotherapy 2016. Clin Exp Nephrol. 2018;22(1):210-44.

20. Janus N, Launay-Vacher V, Byloos E, Machiels JP, Duck L, Kerger J, et al. Cancer and renal insufficiency results of the BIRMA study. Br J Cancer. 2010;103(12):1815-21.

21. Mery B, Guichard JB, Guy JB, Vallard A, Barthelemy JC, Da Costa A, et al. Atrial fibrillation in cancer patients: hindsight, insight and foresight. Int J Cardiol. 2017;240:196-202.

22. Gelosa P, Castiglioni L, Tenconi M, Baldessin L, Racagni G, Corsini A, et al. Pharmacokinetic drug interactions of the nonvitamin $\mathrm{K}$ antagonist oral anticoagulants (NOACs). Pharmacol Res. 2018;135:60-79.

23. Raschi E, Bianchin M, Gatti M, Squizzato A, De Ponti F. Comparative effectiveness and safety of direct oral anticoagulants: overview of systematic reviews. Drug Saf. 2019;42(12): 1409-22.

24. Curigliano G, Shah RR. Safety and tolerability of phosphatidylinositol-3-kinase (PI3K) inhibitors in oncology. Drug Saf. 2019;42(2):247-62.

25. Bellet M, Ahmad F, Villanueva R, Valdivia C, Palomino-Doza J, Ruiz A, et al. Palbociclib and ribociclib in breast cancer: consensus workshop on the management of concomitant medication. Ther Adv Med Oncol. 2019;11:1758835919833867.
26. Shatzel JJ, Daughety MM, Olson SR, Beer TM, DeLoughery TG. Management of anticoagulation in patients with prostate cancer receiving enzalutamide. J Oncol Pract. 2017;13(11):720-7.

27. Peng Y, Cui H, Liu Z, Liu D, Liu F, Song Y, et al. Apatinib to combat EGFR-TKI resistance in an advanced non-small cell lung cancer patient with unknown EGFR status: a case report. Onco Targets Ther. 2017;10:2289-95.

28. Hsyu PH, Pignataro DS, Matschke K. Effect of bosutinib on the absorption of dabigatran etexilate mesylate, a P-glycoprotein substrate, in healthy subjects. Eur J Clin Pharmacol. 2017;73(1):5763.

29. Visentin A, Campello E, Scomazzon E, Spiezia L, Imbergamo S, Pravato S, et al. Dabigatran in ibrutinib-treated patients with atrial fibrillation and lymphoproliferative diseases: experience of 4 cases. Hematol Oncol. 2018;36(5):801-3.

30. Quintavalla R, Lombardi M, Prandoni P, Manotti C, Tadonio I, Re $\mathrm{F}$, et al. Increased dabigatran plasma concentration during ibrutinib treatment: a case of cerebral hemorrhage and successful dabigatran reversal by idarucizumab. Aging Clin Exp Res. 2018;30(1):93-5.

31. Lewicka E, Daniluk P, Lasocka Z, Zarzycka E, DąbrowskaKugacka A, Nabiałek-Trojanowska I, et al. Assessment of dabigatran plasma concentrations may improve the safety of anticoagulation in patients with atrial fibrillation undergoing ibrutinib treatment. Kardiol Pol. 2020. https://doi.org/10.33963/ KP.15255.

32. Waite MMA, Martinelli AW, Preston SD, Gudgin E, Symington E, Rintoul RC, et al. A hypercoagulable state leading to venous limb gangrene associated with occult lung adenocarcinoma. Clin Case Rep. 2019;7(5):888-92.

33. Nassif T, Banchs J, Yusuf SW, Mouhayar E. Acute haemorrhagic tamponade in cancer patients receiving direct oral anticoagulant: case series. Eur Heart J Case Rep. 2017;1(2):ytx018.

34. Khalid M, Khattak F, Ramu V. Cardiovascular side effects of tyrosine kinase inhibitor ibrutinib (imbruvica) and interaction with direct oral anticoagulant. Am J Ther. 2018;25(6):e768-9.

35. Le Guern A, Lebas D, Thillard EM, Martincic C, Wiart T, Modiano P. Hemorrhagic syndrome during cobimetinib therapy: the need for caution in patients receiving new anticoagulant drugs. Ann Dermatol Venereol. 2017;144(5):383-4.

36. Santini D, Citarella F, Vincenzi B, Russano M, Tonini G, Stellato M. Cabozantinib and apixaban: an hitherto unreported interaction. Exp Hematol Oncol. 2019;8:22.

37. Poluzzi E, Raschi E, Diemberger I, De Ponti F. Drug-induced arrhythmia: bridging the gap between pathophysiological knowledge and clinical practice. Drug Saf. 2017;40(6):461-4.

38. Tang N, Li D, Wang X, Sun Z. Abnormal coagulation parameters are associated with poor prognosis in patients with novel coronavirus pneumonia. J Thromb Haemost. 2020;18(4):844-7.

39. McCreary EK, Pogue JM. Coronavirus disease 2019 treatment: a review of early and emerging options. Open Forum Infect Dis. 2020;7(4):ofaa105.

40. Clarivet B, Robin P, Pers YM, Ferreira R, Lebrun J, Jorgensen C, et al. Tocilizumab and mesenteric arterial thrombosis: drug-drug interaction with anticoagulants metabolized by CYP 450 and/or by P-glycoprotein. Eur J Clin Pharmacol. 2016;72(11):1413-4.

41. Lakatos B, Stoeckle M, Elzi L, Battegay M, Marzolini C. Gastrointestinal bleeding associated with rivaroxaban administration in a treated patient infected with human immunodeficiency virus. Swiss Med Wkly. 2014;144:w13906.

42. Corallo CE, Grannell L, Tran H. Postoperative bleeding after administration of a single dose of rivaroxaban to a patient receiving antiretroviral therapy. Drug Saf Case Rep. 2015;2(1):11.

43. Mueck W, Kubitza D, Becka M. Co-administration of rivaroxaban with drugs that share its elimination pathways: pharmacokinetic 
effects in healthy subjects. Br J Clin Pharmacol. 2013;76(3):45566.

44. Stöllberger C, Finsterer J. Relevance of P-glycoprotein in stroke prevention with dabigatran, rivaroxaban, and apixaban. Herz. 2015;40(Suppl 2):140-5.

45. Nisly SA, Stevens BN. Ritonavir- or cobicistat-boosted antiretroviral therapy and direct oral anticoagulants: a case for apixaban. Int J STD AIDS. 2019;30(7):718-22.

46. Kumar P, Gordon LA, Brooks KM, George JM, Kellogg A, McManus M, et al. Differential influence of the antiretroviral pharmacokinetic enhancers ritonavir and cobicistat on intestinal P-glycoprotein transport and the pharmacokinetic/ pharmacodynamic disposition of dabigatran. Antimicrob Agents Chemother. 2017;61(11):e01201-17.

47. George JM, Kuriakose SS, Monroe A, Hou Q, Byrne M, Pau AK, et al. Utilization of direct oral anticoagulants in people with HIV: observational data from the DC cohort. Clin Infect Dis. 2020: ciaa284.

48. Zhang C, Wu Z, Li JW, Zhao H, Wang GQ. The cytokine release syndrome (CRS) of severe COVID-19 and Interleukin-6 receptor (IL-6R) antagonist tocilizumab may be the key to reduce the mortality. Int J Antimicrob Agents. 2020:105954.

49. Lombardy Section Italian Society Infectious And Tropical Diseases. Vademecum for the treatment of people with COVID19. Edition 2.0, 13 March 2020. Infez Med. 2020;28(2):143-52.

50. Jover R, Bort R, Gómez-Lechón MJ, Castell JV. Down-regulation of human CYP3A4 by the inflammatory signal interleukin-6: molecular mechanism and transcription factors involved. FASEB J. 2002;16(13):1799-801.

51. Lee EB, Daskalakis N, Xu C, Paccaly A, Miller B, Fleischmann R, et al. Disease-drug interaction of sarilumab and simvastatin in patients with rheumatoid arthritis. Clin Pharmacokinet. 2017;56(6):607-15.

52. Schmitt C, Kuhn B, Zhang X, Kivitz AJ, Grange S. Disease-drugdrug interaction involving tocilizumab and simvastatin in patients with rheumatoid arthritis. Clin Pharmacol Ther. 2011;89(5):73540.

53. Testa S, Prandoni P, Paoletti O, Morandini R, Tala M, Dellanoce $\mathrm{C}$, et al. Direct oral anticoagulant plasma levels' striking increase in severe COVID-19 respiratory syndrome patients treated with antiviral agents: the Cremona experience. J Thromb Haemost. 2020;18:1320-3. https://doi.org/10.1111/jth.14871.

54. Testa S, Paoletti O, Giorgi-Pierfranceschi M, Pan A. Switch from oral anticoagulants to parenteral heparin in SARS-CoV-2 hospitalized patients. Intern Emerg Med. 2020;15:751-3. https://doi. org/10.1007/s11739-020-02331-1.

55.• Bikdeli B, Madhavan MV, Jimenez D, Chuich T, Dreyfus I, Driggin E, et al. COVID-19 and thrombotic or thromboembolic disease: implications for prevention, antithrombotic therapy, and follow-up. J Am Coll Cardiol. 2020;(20):35008-7 The first comprehensive assessment of thrombotic issues in COVID-19.

56. Tamargo J, Caballero R, Delpón E. Cancer chemotherapy and cardiac arrhythmias: a review. Drug Saf. 2015;38(2):129-52.

57. Farmakis D, Parissis J, Filippatos G. Insights into onco-cardiology: atrial fibrillation in cancer. J Am Coll Cardiol. 2014;63(10): 945-53.

58. Guha A, Dey AK, Jneid H, Ibarz JP, Addison D, Fradley M. Atrial fibrillation in the era of emerging cancer therapies. Eur Heart J. 2019;40(36):3007-10.

59. Alexandre J, Moslehi JJ, Bersell KR, Funck-Brentano C, Roden DM, Salem JE. Anticancer drug-induced cardiac rhythm disorders: current knowledge and basic underlying mechanisms. Pharmacol Ther. 2018;189:89-103.

60. Alexandre J, Salem JE, Moslehi J, Sassier M, Ropert C, Cautela J, et al. Identification of anticancer drugs associated with atrial fibrillation - analysis of the WHO pharmacovigilance database. Eur
Heart J Cardiovasc Pharmacother. 2020:pvaa037. https://oi.org/ 10.1093/ehjcvp/pvaa037.

61. Kim DH, Rogers JR, Fulchino LA, Kim CA, Solomon DH, Kim SC. Bisphosphonates and risk of cardiovascular events: a metaanalysis. PLoS One. 2015;10(4):e0122646. https://doi.org/10. 1371/journal.pone.0122646 eCollection 2015.

62. Tufano A, Galderisi M, Esposito L, Trimarco V, Sorriento D, Gerusalem G, et al. Anticancer drug-related nonvalvular atrial fibrillation: challenges in management and antithrombotic strategies. Semin Thromb Hemost. 2018;44(4):388-96.

63. Salem JE, Manouchehri A, Bretagne M, Lebrun-Vignes B, Groarke JD, Johnson DB, et al. Cardiovascular toxicities associated with ibrutinib. J Am Coll Cardiol. 2019;74(13):1667-78.

64. Tamargo J, Caballero R, Delpón E. Drug-induced atrial fibrillation. Expert Opin Drug Saf. 2012;11(4):615-34.

65. Marrouche NF, Brachmann J, Andresen D, Siebels J, Boersma L, Jordaens L, et al. Catheter ablation for atrial fibrillation with heart failure. N Engl J Med. 2018;378(5):417-27.

66. Khairy P, Chauvet P, Lehmann J, Lambert J, Macle L, Tanguay $\mathrm{JF}$, et al. Lower incidence of thrombus formation with cryoenergy versus radiofrequency catheter ablation. Circulation. 2003;107(15):2045-50.

67. Giustozzi M, Ali H, Reboldi G, Balla C, Foresti S, de Ambroggi $\mathrm{G}$, et al. Safety of catheter ablation of atrial fibrillation in cancer survivors. J Interv Card Electrophysiol. 2020. https://doi.org/10. 1007/s10840-020-00745-7.

68. Ipsen S, Blanck O, Oborn B, Bode F, Liney G, Hunold P, et al. Radiotherapy beyond cancer: target localization in real-time MRI and treatment planning for cardiac radiosurgery. Med Phys. 2014;41(12):120702.

69. Raskob GE, van Es N, Verhamme P, Carrier M, Di Nisio M, Garcia D, et al. Edoxaban for the treatment of cancer-associated venous thromboembolism. N Engl J Med. 2018;378(7):615-24.

70. Stockbridge N, Morganroth J, Shah RR, Garnett C. Dealing with global safety issues : was the response to QT-liability of noncardiac drugs well coordinated? Drug Saf. 2013;36(3):167-82.

71. Diemberger I, Raschi E, Trifirò G. Balancing the need for personalization of QT correction and generalization of study results: going beyond thorough QT studies. Clin Drug Investig. 2017;37(10):985-8.

72. Woosley RL, Black K, Heise CW, Romero K. CredibleMeds.org: what does it offer? Trends Cardiovasc Med. 2018;28(2):94-9.

73. Shah RR, Morganroth J, Shah DR. Cardiovascular safety of tyrosine kinase inhibitors: with a special focus on cardiac repolarisation (QT interval). Drug Saf. 2013;36(5):295-316.

74. Shah RR, Morganroth J. Update on cardiovascular safety of tyrosine kinase inhibitors: with a special focus on QT interval, left ventricular dysfunction and overall risk/benefit. Drug Saf. 2015;38(8):693-710.

75. Ismail $\mathrm{M}$, Khan $\mathrm{S}$, Khan $\mathrm{F}$, Noor $\mathrm{S}$, Sajid H, Yar $\mathrm{S}$, et al. Prevalence and significance of potential drug-drug interactions among cancer patients receiving chemotherapy. BMC Cancer. 2020;20(1):335.

76. Kim SH, Suh Y, Ah YM, Jun K, Lee JY. Real-world prevalence of potential drug-drug interactions involving oral antineoplastic agents: a population-based study. Support Care Cancer. 2019;28: 3617-26. https://doi.org/10.1007/s00520-019-05204-2.

77. Raschi E, Vasina V, Poluzzi E, De Ponti F. The hERG K+ channel: target and antitarget strategies in drug development. Pharmacol Res. 2008;57(3):181-95.

78. Yang T, Meoli DF, Moslehi J, Roden DM. Inhibition of the $\alpha$ subunit of phosphoinositide 3-kinase in heart increases late sodium current and is arrhythmogenic. J Pharmacol Exp Ther. 2018;365(3):460-6.

79. Lu Z, Wu CY, Jiang YP, Ballou LM, Clausen C, Cohen IS, et al. Suppression of phosphoinositide 3-kinase signaling and alteration 
of multiple ion currents in drug-induced long QT syndrome. Sci Transl Med. 2012;4(131):131ra50.

80. Roden DM. A current understanding of drug-induced QT prolongation and its implications for anticancer therapy. Cardiovasc Res. 2019;115(5):895-903 An updated review on mechanisms and implications of drug-induced QT prolongation by anticancer agents.

81. Spence S, Deurinck M, Ju H, Traebert M, McLean L, Marlowe J, et al. Histone deacetylase inhibitors prolong cardiac repolarization through transcriptional mechanisms. Toxicol Sci. 2016;153(1): 39-54.

82. Li P, Kurata Y, Endang M, Ninomiya H, Higaki K, Taufiq F, et al. Restoration of mutant hERG stability by inhibition of HDAC6. J Mol Cell Cardiol. 2018;115:158-69.

83. Shah RR, Shah DR. Safety and tolerability of epidermal growth factor receptor (EGFR) tyrosine kinase inhibitors in oncology. Drug Saf. 2019;42(2):181-98.

84. Rocco D, Battiloro C, Della Gravara L, Gridelli C. Safety and tolerability of anaplastic lymphoma kinase inhibitors in nonsmall-cell lung cancer. Drug Saf. 2019;42(2):199-209.

85. Puccini A, Marín-Ramos NI, Bergamo F, Schirripa M, Lonardi S, Lenz HJ, et al. Safety and tolerability of c-MET inhibitors in cancer. Drug Saf. 2019;42(2):211-33.

86. Shah RR. Safety and tolerability of histone deacetylase (HDAC) inhibitors in oncology. Drug Saf. 2019;42(2):235-45.

87. de Weerdt I, Koopmans SM, Kater AP, van Gelder M. Incidence and management of toxicity associated with ibrutinib and idelalisib: a practical approach. Haematologica. 2017;102(10): 1629-39.

88. Carpenter RL, Ray H. Safety and tolerability of sonic hedgehog pathway inhibitors in cancer. Drug Saf. 2019;42(2):263-79.

89. Pezo RC, Yan AT, Earle C, Chan KK. Underuse of ECG monitoring in oncology patients receiving QT-interval prolonging drugs. Heart. 2019;105(21):1649-55.

90. Diemberger I, Massaro G, Cubelli M, Rubino D, Quercia S, Martignani C, et al. Repolarization effects of multiple-cycle chemotherapy and predictors of QTc prolongation: a prospective female cohort study on >2000 ECGs. Eur J Clin Pharmacol. 2015;71(8):1001-9.

91. Guzik TJ, Mohiddin SA, Dimarco A, Patel V, Savvatis K, MarelliBerg FM, et al. COVID-19 and the cardiovascular system: implications for risk assessment, diagnosis, and treatment options. Cardiovasc Res. 2020:cvaa106. https://doi.org/10.1093/cvr/ cvaa106.

92. Hendren NS, Drazner MH, Bozkurt B, Cooper LT Jr. Description and proposed management of the acute COVID-19 cardiovascular syndrome. Circulation. 2020;141:1903-14. https://doi.org/10. 1161/CIRCULATIONAHA.120.047349.

93. Lazzerini PE, Boutjdir M, Capecchi PL. COVID-19, arrhythmic risk and inflammation: mind the gap! Circulation. 2020. https:// doi.org/10.1161/CIRCULATIONAHA.120.047293.

94. Capel RA, Herring N, Kalla M, Yavari A, Mirams GR, Douglas $\mathrm{G}$, et al. Hydroxychloroquine reduces heart rate by modulating the hyperpolarization-activated current If: novel electrophysiological insights and therapeutic potential. Heart Rhythm. 2015;12(10): 2186-94.
95. Gollob MH. COVID-19, clinical trials and QT-prolonging prophylactic therapy in healthy subjects: first, do no harm. J Am Coll Cardiol. 2020;(20):35228-1.

96. Driggin E, Madhavan MV, Bikdeli B, Chuich T, Laracy J, BiondiZoccai G, et al. Cardiovascular considerations for patients, health care workers, and health systems during the COVID-19 pandemic. J Am Coll Cardiol. 2020;75(18):2352-71.

97. Trifirò G, de Ridder M, Sultana J, Oteri A, Rijnbeek P, Pecchioli $\mathrm{S}$, et al. Use of azithromycin and risk of ventricular arrhythmia. CMAJ. 2017;189(15):E560-8.

98. Lazzerini PE, Laghi-Pasini F, Boutjdir M, Capecchi PL. Cardioimmunology of arrhythmias: the role of autoimmune and inflammatory cardiac channelopathies. Nat Rev Immunol. 2019;19(1):63-4.

99. Lazzerini PE, Capecchi PL, Laghi-Pasini F. Systemic inflammation and arrhythmic risk: lessons from rheumatoid arthritis. Eur Heart J. 2017;38(22):1717-27.

100. Lazzerini PE, Acampa M, Capecchi PL, Fineschi I, Selvi E, Moscadelli V, et al. Antiarrhythmic potential of anticytokine therapy in rheumatoid arthritis: tocilizumab reduces corrected QT interval by controlling systemic inflammation. Arthritis Care Res. 2015;67(3):332-9.

101. Bertero E, Ameri P, Maack C. Bidirectional relationship between cancer and heart failure: old and new issues in cardio-oncology. Card Fail Rev. 2019;5(2):106-11.

102. De Jesus NM, Wang L, Lai J, Rigor RR, Francis Stuart SD, Bers DM, et al. Antiarrhythmic effects of interleukin 1 inhibition after myocardial infarction. Heart Rhythm. 2017;14(5):727-36.

103. Emmi G, Urban ML, Imazio M, Gattorno M, Maestroni S, Lopalco G, et al. Use of interleukin-1 blockers in pericardial and cardiovascular diseases. Curr Cardiol Rep. 2018;20(8):61.

104. Sapp JL, Alqarawi W, MacIntyre CJ, Tadros R, Steinberg C, Roberts JD, et al. Guidance on minimizing risk of drug-induced ventricular arrhythmia during treatment of COVID-19: a statement from the Canadian Heart Rhythm Society. Can J Cardiol. 2020;(20):30325-1. https://doi.org/10.1016/j.cjca.2020.04.003.

105. Naksuk N, Lazar S, Peeraphatdit TB. Cardiac safety of off-label COVID-19 drug therapy: a review and proposed monitoring protocol. Eur Heart J Acute Cardiovasc Care. 2020: 2048872620922784-221. https://doi.org/10.1177/ 2048872620922784.

106. Giudicessi JR, Noseworthy PA, Friedman PA, Ackerman MJ. Urgent guidance for navigating and circumventing the QTcprolonging and torsadogenic potential of possible pharmacotherapies for coronavirus disease 19 (COVID-19). Mayo Clin Proc. 2020;(20):30313-X. https://doi.org/10.1016/j.mayocp.2020.03. 024.

107. Sacher F, Fauchier L, Boveda S, de Chillou C, Defaye P, Deharo JC, et al. Electrophysiology of the French Society of Cardiology, the Board of the French Society of Cardiology. Use of drugs with potential cardiac effect in the setting of SARS-CoV-2 infection. Arch Cardiovasc Dis. 2020;(20):30100-5. https://doi.org/10. 1016/j.acvd.2020.04.003.

Publisher's Note Springer Nature remains neutral with regard to jurisdictional claims in published maps and institutional affiliations. 